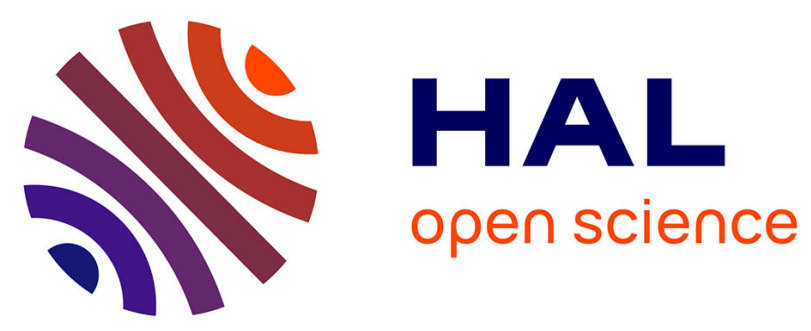

\title{
Evidence-based treatments for youths with severely dysregulated mood: a qualitative systematic review of trials for SMD and DMDD
}

Xavier Benarous, Angèle Consoli, Jean-Marc Guilé, Sébastien Garny de La Rivière, David Cohen, Bertrand Olliac

\section{To cite this version:}

Xavier Benarous, Angèle Consoli, Jean-Marc Guilé, Sébastien Garny de La Rivière, David Cohen, et al.. Evidence-based treatments for youths with severely dysregulated mood: a qualitative systematic review of trials for SMD and DMDD. European Child and Adolescent Psychiatry, 2016, pp.1-19. 10.1007/s00787-016-0907-5 . hal-01379080

\section{HAL Id: hal-01379080 \\ https://hal.sorbonne-universite.fr/hal-01379080}

Submitted on 11 Oct 2016

HAL is a multi-disciplinary open access archive for the deposit and dissemination of scientific research documents, whether they are published or not. The documents may come from teaching and research institutions in France or abroad, or from public or private research centers.
L'archive ouverte pluridisciplinaire HAL, est destinée au dépôt et à la diffusion de documents scientifiques de niveau recherche, publiés ou non, émanant des établissements d'enseignement et de recherche français ou étrangers, des laboratoires publics ou privés. 


\section{Evidence-based treatments for youths with severely dysregulated mood: a qualitative systematic review of trials for SMD and DMDD}

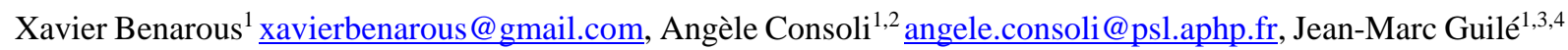
guile.jean-marc@chu-amiens.fr, Sébastien Garny de La Rivière ${ }^{3}$ garnydelariviere.sebastien@chu-amiens.fr, David Cohen ${ }^{1,5}$ david.cohen@psl.aphp.fr, Bertrand Olliac ${ }^{1,6}$ bertrand.olliac@gmail.com

${ }^{1}$ Department of Child And Adolescent Psychiatry, Pitié-Salpêtrière Hospital, 47-83 boulevard de l'Hôpital, 75013 Paris, France

${ }^{2}$ INSERM U-669, PSIGIAM, Paris, France

${ }^{3}$ Groupe de Recherches sur l'Analyse Multimodale de la Fonction Cérébrale, INSERM U1105, CHU, Université Picardie Jules Verne, Amiens, France

${ }^{4}$ Department of Psychiatry, McGill University, Montreal, Canada

${ }^{5}$ CNRS UMR 7222, Institute for Intelligent Systems and Robotics-ISIR, Paris, France

${ }^{6}$ Pôle Hospitalo-Universitaire de psychiatrie de l'enfant et de l'adolescent, Centre Hospitalier Esquirol, Limoges, France

Address of correspondence: Xavier Benarous, Department of Child And Adolescent Psychiatry, Pitié-Salpêtrière Hospital, 47-83 boulevard de l'Hôpital, 75013 Paris, France

Email: xavierbenarous@gmail.com

Phone: $+33(0) 603260193$

Fax: $+33(0) 142162331$

Category: Review article

Abbreviated title: Treatments for youths with SMD and DMDD

Conflict of interest: On behalf of all authors, the corresponding author states that there is no conflict of interest. 


\begin{abstract}
The aim of this literature review was to examine the evidence for psychotherapeutic and pharmacological treatments in subjects with severely dysregulated mood and to identify potential areas for improvements in research designs. A literature search was conducted using several databases for published (PubMed, PsycINFO) and ongoing (clinical trial registries) studies conducted in youths who met NIMH's criteria for Severe Mood Dysregulation (SMD) or the DSM-5 diagnosis of Disruptive Mood Dysregulation Disorder (DMDD). Eight completed studies were identified: three randomized trials, four open pilot studies and one case report. Seven ongoing studies were found in trial registries. The available evidence suggests potential efficacy of psychotherapies which have previously been developed for internalizing and externalizing disorders. The two main pharmacological strategies tested are, first, a monotherapy of psychostimulant or atypical antipsychotic such as risperidone, already used in the treatment of severe irritability in youths with developmental disorders; and second, the use of a serotonergic antidepressant as an add-on therapy in youths treated with psychostimulant. Ongoing studies will further clarify the effectiveness of psychotherapeutic interventions for DMDD individuals and whether they should be given alone or in conjunction with other treatments. The short duration of the trials for a chronic disorder, the low number of studies, the lack of placebo or active comparator arm, and restrictive inclusion criteria in most of the controlled trials dramatically limit the interpretation of the results. Finally, future research should be conducted across multiple sites, with standardized procedures to measure DMDD symptoms reduction, and include a run-in period to limit placebo effect.
\end{abstract}

KEYWORDS: disruptive mood dysregulation disorder; severe mood dysregulation; psychotherapy; pharmacotherapy; therapeutics; irritability 


\section{INTRODUCTION}

\subsection{General background}

Children with severely dysregulated mood have become diagnostic and therapeutic challenges over the last two decades within the context of pediatric bipolar controversy [1-4]. In view of facilitating research programs researchers at the U.S. National Institute of Mental Health (NIMH) operationalized the criteria of "Severe Mood Dysregulation" (SMD), a syndrome characterized by chronic abnormal levels of anger or sadness, hyperarousal and heightened verbal or physical reactivity [5]. On the grounds of studies conducted in youths with SMD and in view of improving mental health care of youths with chronic irritability, the Disruptive Mood Dysregulation Disorder (DMDD) was introduced as a new diagnosis in the Diagnostic and Statistical Manual of Mental Disorders, fifth edition (DSM-5) within the Depressive Disorders section [6]. Youths with DMDD present chronic irritability combined with severe and recurrent episodes of temper outburst inconsistent with their developmental level at least three times per week and occurring in different settings (e.g., in family, school). These symptoms should persist more than twelve months with no symptom-free period longer than three months and with an initial onset prior to the age of 10. Prevalence of DMDD is reported to be around $8.2 \%$ in general population [7-9] and around $26-31 \%$ in clinical settings $[10,11]$. There is much evidence supporting that DMDD symptoms severely affect a youth's level of social functioning [7,8] and that such negative effects could persist into adulthood [9]. Copeland et al. showed that as adults youths with DMDD present a much higher level of functional impairments (i.e., adverse health outcomes, financial problems, police contact, and low educational attainment) than those with any other psychiatric disorders (e.g., depressive 
disorders, anxiety disorders, attention deficit hyperactivity disorder ADHD, disruptive disorder, or substance disorders) [9].

\subsection{Phenomenology of youths with severely dysregulated mood}

Mood dysregulation (i.e., severe irritability and high level of anger) is seen as a transdiagnostic symptom, with a dimensional continuum from its typical expression in normal development of children and adolescences to severely impairing forms in psychiatric disorders [12]. In this vein, the development of studies based on specific cognitive and emotional domains rather than DSM-5 categories of disorders has been encouraged, in particular research aligned with the framework of the Research Domain Criteria articulated by the NIMH. This strategy has led to significant improvements in our knowledge of the mechanisms underlying varying aspects of mood dysregulation in youths. Such progress may ultimately lead to discovering new markers of the disorder and targets for specific interventions. The study published by Stoddard et al. [13] provides a good example of how these different levels of analysis can be integrated in research based on a dimensional view of psychopathology; with the articulation between impaired neural substrates (i.e., orbitofrontal cortex and amygdala activation), a clinical or psychological marker (i.e., the result at a face-emotion labelling task), and a therapeutic (i.e., computer-based) intervention targeting interpretation bias.

A different approach has been used in the present review as we specifically focused on studies where the clinical categories of SMD or DMDD were applied to define the population of interest. The SMD (i.e., the research syndrome) and then DMDD (i.e., the DMS-5 diagnosis) criteria were originally developed in view of facilitating the identification of youths with severe, persistent and functionally impairing forms of irritability, who were likely to fulfil criteria for different disorders at different times (“diagnostically homeless") [14]. The development of a 
specific category for these youths was endorsed due to the need to facilitate access to treatment, to reduce the rate of misdiagnosis especially early-onset bipolar disorder, and finally to reduce excessive and inappropriate medication. The inclusion of the DMDD in the $5^{\text {th }}$ version of the DSM has encouraged the development of evidence-based trials which would have been difficult if mood dysregulation had been operationalized as a dimension. The use of specific disorders for youths with severely dysregulated mood was encouraged to limit the confusion with earlyonset bipolar disorder and to enhance a more rational use of psychotropic medications (in particular, mood stabilizers). This issue was regarded as a major public health challenge considering the trend to overmedication and polypharmacy observed in prepubertal youths [15]. Mood dysregulation can be found in youths with various forms of psychopathology for example among youths with autistic spectrum disorder and sensory integration issues or in patients with post-traumatic stress disorder who experience episodic hyperarousal [16]. If a treatment has a positive impact only in patients with a comorbid psychiatric disorder, its overall benefit in clinical trial would be under- or overestimated with regards to its prevalence in the sample studied. The use of a categorical approach can help to explore the heterogeneity of the response to treatment in DMDD youths, for example through secondary analyses of subgroups with different associated psychiatric disorders.

\subsection{Validity of SMD and DMDD diagnoses}

Evidence for the validity of SMD and later DMDD diagnosis was raised on the ground of studies exploring the internal and external validity of these disorders, especially data on discriminant validity [17,18], familial studies [19], psychophysiological and neuroimaging studies [20-23], as well as response to pharmacological treatment [24,14]. However, concerns have been raised regarding different aspects of the diagnostic validity: the paucity of data 
regarding reliability in literature, the difficulty in delineating the normal and abnormal mood lability in children, and above all the high rate of overlap with others psychiatric disorders, especially ADHD and ODD $[8,10,11]$. In addition, other aspects of child psychopathology are still rarely taken into consideration in these studies regarding some aspects of a child's individual characteristics (e.g., temperamental traits and attachment style) and environmental backgrounds (e.g., parent-child interaction patterns, possibility of co-occurring maltreatment). Lastly, significant changes were made in the process of integrating the category of SMD in DSM-5 including removing the criterion of hyperarousal (e.g., insomnia, agitation, distractibility, racing thoughts/flight of ideas, pressured speech, and intrusiveness), and the criterion of low intelligence (IQ<80) from the exclusionary criteria, as well as lowering the age of onset from 12 to 10 years old [6]. Such differences are not trivial and could affect the comorbidity profiles of SMD and DMDD. For example, despite the lack of direct comparison between the two clinical entities, data suggests that DMDD most often co-occurs with depressive disorders and ODD and less with ADHD compared to SMD [10].

\subsection{Therapeutic strategies}

Little is known about effective treatments of SMD and DMDD. The DSM-5 Task Force suggested that "individual therapy, as well as work with the child's family and/or school [and] the use of medication to help address specific symptoms" could be useful for DMDD youths [6]. However, the use of treatments targeting symptoms without considering the overall diagnosis has been criticized as it may contribute to the high rates of polypharmacy in this population [25-27]. Given that SMD and DMDD frequently occur with comorbid psychiatric disorders $[8,10,11,28-30]$, it has been suggested that therapeutic interventions should primarily focus on treating associated disorders. However, studies examining the benefit of 
psychotherapy or pharmacotherapy on mood dysregulation in different psychiatric disorders are somewhat mixed [31,32]. Galanter et al. [32] found that the higher baseline levels of psychopathology of children with ADHD and mood dysregulation, compared to those without prominent mood dysregulation, persisted after intensive multimodal treatments for ADHD, suggesting the need for additional treatment. In a recent systematic review, Tourian et al. examined empirical evidence supporting the use of pharmacological treatments for severe anger/irritability symptoms in youths [4]. They found that pharmacotherapeutic treatment for both aggression and chronic irritability includes various options, such as antidepressants, especially selective norepinephrine reuptake inhibitors, mood stabilizers, psychostimulants, antipsychotics, and alpha-2 agonists. However, such findings are difficult to generalize, since, as the authors noted, a majority of the study was conducted in small and specific populations (e.g., youths with developmental disorders). Even if no treatment algorithm for severe persistent irritability in youths can be derived from this data, that study can be regarded as a first step for providing evidence-based treatments for children with DMDD as it informed about the potentially effective treatments. However, in view of meeting the needs of clinician and researcher, randomized controlled clinical trials (RCTs) specifically developed for youths with SMD or DMDD are required.

The high rates of comorbidity of SMD and DMDD with externalized disorders $[8,10,11,28-30]$ raise questions about the best ways to conduct such trials. How should pharmacological and psychotherapeutic interventions for DMDD be tested within existing therapeutic strategies for externalized disorders? Which treatments should be allowed in the control group? How should the severity of mood symptoms be measured? Is the inclusion of only DMDD subjects without psychiatric comorbidity an acceptable strategy?

\subsection{Aims of the present review}




\section{METHODS}

\subsection{Review}

The systematic review was conducted following the recommendations outlined in the PRISMA guide (Figure 1) [33]. Titles and abstracts were scanned for relevance. Full texts were ordered in case of uncertainty to maximize sensitivity. Reference lists of retrieved systematic reviews were checked. All full texts were checked for eligibility. Any original study (open trial, double-blind trial whether randomized control or not), case-report, caseseries, meta-analysis and systematic review of pharmacological and non-pharmacological intervention was eligible for inclusion in this review. Abstracts and editorials were excluded. As DMDD was previously known in the literature under the alias of Severe Mood Dysregulation (SMD), studies conducted among youths with SMD were included in the current analysis. Study participants had to be diagnosed with SMD or DMDD, and to be 
between five and 18 years old, or the mean age of the participants had to fall within the aforementioned age range.

[Insert Figure 1, about here]

\subsection{Search method for identification of studies}

Relevant articles for this study were obtained through Cochrane Central Register of Controlled Trials (CENTRAL), Pubmed, Medline, PsychINFO, PsychINDEXplus and Dissertation Abstracts. Each database was searched from January 2001 to December 2015. In addition, we hand searched reference lists of identified articles and pertinent reviews for additional studies. References from the reviewed articles were also screened to find more articles of interest. Furthermore, clinical trials registries (http://www.clinicaltrials.gov of the US National Institutes of Health and the WHO International Clinical Trials Registry Platform, ICTRP) were searched for ongoing trials. We used the following search terms: "Disruptive mood dysregulation disorder" OR "Severe mood dysregulation" OR “Temper outburst” AND “Therapeutics” OR “Clinical protocols" OR “Treatment” OR "Pharmacotherapy” OR "Psychotherapy". Authors independently screened potential studies, after reading the full article, for inclusion in the review, and the results were collated. The systematic review yielded 86 hits, with 29 being a duplicate; 21 hits could be excluded based on the information in the title or abstract. The full texts of 36 hits were critically reviewed leading to exclusion of another 21 articles because these were only reviews or comments and no new original data were included; or the research was not conducted in DMDD/SMD youths. A list of 15 studies was generated: eight completed studies (one case report, four open pilot studies and three RCTs) and seven ongoing studies found in trial registries. 


\subsection{Data and analysis}

Data and information extractions from each study were performed independently by the two first authors. For each study under review, year of publication and references were extracted. In order to summarize the treatment attributes in each report we collected the following information: description of medication, length of treatment, and dose received. Information on additional or adjunctive interventions was also collected. Additional information regarding the attributes of participants enrolled in the studies were extracted and were as follows: age, gender, how the diagnosis was made, treatment setting, comorbid conditions, sociodemographic data, and screening tools used. Although a meta-analytic review has been preferable, the diversity of statistical methods and measurement practices across studies did not allow for the calculation of pooled effect size. We categorized the level of evidence presented in each paper using the United States Preventive Services Task Force (USPSTF) criteria [35]. According to this schematic, level I evidence denotes having at least one well-designed RCT supporting a treatment's possible efficacy. Level II-1 requires a welldesigned controlled trial without randomization, level II-2 requires at least one well-designed cohort or case-control study, and level II-3 requires a multiple time series design. We excluded level III evidence (opinions of respected authorities based on clinical experience or descriptive studies) from the present review.

\section{RESULTS}

\subsection{Psychotherapeutic interventions for DMDD}




\subsubsection{Completed studies}

Only three studies were eligible for the review (Table 1): an exploratory analysis from a controlled study of multiple interventions for ADHD children [36], the subsequent open uncontrolled feasibility study conducted by the same research team on youths with ADHD and SMD [37], and an open pilot uncontrolled study on DMDD youths [13].

Waxmonsky et al. (2008) conducted secondary analysis of data from the 2003-2004 ADHD Summer Treatment Program (ADHD-STP), a research program for children aged 512 in the form of an intensive 9-week therapeutic summer camp [38]. The initial study aimed to assess the relative efficacy and synergistic effects of differential doses of behavioural and pharmacologic interventions in ADHD youths. Among the 106 participants33 fulfilled NIMH criteria for SMD (mean age 8.0 \pm 2.1 years and $8.7 \pm 2.0$ years for non SMD group). The behavioral intervention consisted of daily social skills training and a reward-based learning program (detailed in [39]). This treatment varied in frequency every three weeks with the order: no behavior modification, low-intensity (i.e., weekly sessions) and high-intensity (i.e., daily sessions). Clinicians rating mood symptoms were not blind to treatments status. There was no evidence of differential treatment efficacy or tolerability on ADHD symptoms between the participants with and without SMD, even though those with SMD were more likely to remain significantly impaired at home than non-SMD subjects. After nine weeks, multimodal treatment produced a $34 \%$ reduction in YMRS ratings in SMD subjects $(p<$ $0.001)$.

In an open-label uncontrolled rater-blind study, Waxmonsky and colleagues examined the feasibility and preliminary efficacy of a psychotherapeutic program that integrated components of CBT focusing on affect regulation and parent training intervention [37]. The seven included children (mean age $8.7 \pm 1.6$ years) presented ADHD and the NIMH criteria 
for SMD. All participants were male. All of the children took stimulant medication for ADHD were assessed using the depression and mania modules from the Washington University Kiddie Schedule for Affective Disorders and Schizophrenia (WASH-U-KSADS). The sessions consisted of 105-minute concurrent parent and child meetings. Six of the seven families (86\%) completed at least seven of the nine weeks in the program. Over the 16 week follow-up, participants showed a reduction in the level of depressive symptoms (CDRS-R, $d=1.17$ ) and externalizing symptoms (ADHD: $d=0.30$; ODD: $d=0.26$; CD: $d=0.27$ ). Authors interpreted the reduction in YMRS score $(d=0.81)$ as an improvement in mood lability among participants.

In an open-label uncontrolled study, Stoddard and colleagues examined the preliminary efficacy of an intervention based on four session of computer-based Hostile Interpretation Therapy [13]. The 14 included children (mean age $14.1 \pm 2.4$ years) presented DMDD. The gender ratio was 8:6 for female. DMDD symptoms were assessed using the Affective Reactivity Index and the Clinical Global Impression- Improvement scale. Training is designed to shift interpretation of ambiguous morphs bias toward happy judgments. Ten subjects completed an implicit functional MRI face-emotion processing task. Active training is associated with a shift in balance point toward more happy judgments (use as a proxy for hostile attribution bias) ( $\beta=2.25$ morphs). Evidence suggests that active training may be associated with decreased irritability ( $\beta=-1.57$ in parent-report ARI score, no significant change in self-report) and changes in activation patterns in the lateral orbitofrontal cortex.

\subsubsection{Ongoing studies}

Four trials were found searching the clinical trials registries that are underway. 
The group from Yale University started a randomized open-label controlled study in

May 2013 to examine feasibility and preliminary efficacy of Dialectical Behaviour Therapy adapted to children (DBT-C) (NCT01862549). The study targets to include 60 7-12 year old children meeting DSM-5 criteria for DMDD. Participants are randomly assigned to receive one of two treatments for 30 weeks: DBT-C or enhanced care (active control condition). Participants on the DBT-C arm received two pre-treatment sessions and 24 treatment sessions with once per week meetings, including $30 \mathrm{~min}$ individual child therapy, 20 min meeting with a caregiver and 40 min of skills training with both. Enhanced care consists of supportive individual psychotherapy, such as cognitive behavioural skills training and adjunctive family interventions (e.g., parenting skills training, structuring household environment, and safety planning). After the acute 32-week intervention period, 3-month follow-up assessments are conducted. The primary outcome is the attendance and drop-out rate measure, the level of satisfaction and compliance at 32 weeks; secondary end-points are reduction in DMDD symptoms and disruptive problems, psychosocial functioning and mental health service use. Estimated primary completion date of the study is July 2015.

The second ongoing study investigates the feasibility and acceptability of Interpersonal Psychotherapy for youths with SMD (IPT-SMD). A monocentric uncontrolled open-label study (NCT01591564) started in May 2012 and targeted to include five subjects who meet NIMH criteria for SMD. Youth receive weekly therapy sessions for 16 weeks and then bi-weekly sessions until week 20. Parent sessions are also included. The primary outcome is the retention rate and secondary end-points include various measures of clinical improvement. The investigators hypothesized that retention rates will be above $80 \%$ and the satisfaction score above six on a seven point scale. Although the results of this research have not yet been published, the same research team started a randomized rater-blind controlled study in October 2013 to test the effectiveness of Interpersonal Psychotherapy for Youth with 
Mood and Behaviour Dysregulation (IPT-MBD) on a more important sample size and allow

for a longer follow-up time (NCT01962623). IPT-MBD is nearly identical to IPT-SMS, except that bi-weekly sessions last until week 24 . This study targets to include 44 youths between 13 and 17 years meeting criteria for SMD. Primary and secondary outcomes are similar to prior research. Estimated primary completion date of the study is August 2016. A monocentric open-label uncontrolled study is underway since August 2015 to compare the efficacy of CBT and Interpretation Bias Training (IBT) on DMDD (NCT02531893). IBT is a newly developed computer-based training focusing on the socioemotional information process impairments described in youths with severe irritability (e.g., anger attribution bias). IBT is performed during 14 sessions over 10 weeks (four sessions in four days, followed by eight weekly booster sessions after a two week delay) and CBT consists of 12-16 weekly meetings. Primary outcomes are improvement in the Clinical Global Impressions-Improvement score (CGI-I) and changes in irritability score using the Affective Reactivity Index (ARI). A four-week wash-out period is planned for those who participate in both treatments. Estimated primary completion date of the study is August 2019.

[Insert Table 1 about here]

\subsection{Pharmacological treatments for DMDD}

\subsubsection{Completed studies}

Only four completed pharmacological studies were eligible for the review (Table 1). In the secondary analysis of data from the 2003-2004 ADHD Summer Treatment Program, Waxmonsky et al. examined the effectiveness of different doses of methylphenidate (MPH) in SMD symptoms in children aged 5-12 with ADHD [36]. All subjects in each 
psychotherapeutic group were treated with increasing MPH doses (placebo, $0.15 \mathrm{mg} / \mathrm{kg}, 0.3$

$\mathrm{mg} / \mathrm{kg}$, and $0.6 \mathrm{mg} / \mathrm{kg}$ ). As mentioned above, multimodal treatment produced a $34 \%$ reduction in YMRS ratings in SMD subjects.

Dickstein et al. led a placebo-controlled randomized trial to test the efficacy of lithium in SMD [24]. At admission 7-17 year old youths with SMD were tapered off previously prescribed medication. Those who continued to meet SMD criteria after a 2-week, singleblind, placebo run-in were randomized to a 6-week double-blind trial of either lithium $(n=14)$ or placebo $(n=11)$. The primary outcome measure was the CGI-I score less than four at trial's end. Magnetic resonance spectroscopy (MRS) was performed in all participants to measure biological markers known to be associated with lithium activity (i.e., myoinositol, N-acetylaspartate and combined glutamate). Almost half of the subjects $(n=20)$ were not randomized due to significant clinical improvement during the placebo run-in. Among randomized patients, there were no significant between-group differences in either clinical or MRS outcome measures.

Krieger et al. conducted an open-label trial to determine the effectiveness of risperidone on youths with DMDD [40]. Of the 97 subjects initially assessed for severe irritability symptoms only 21 met DMDD criteria and were finally enrolled in the study. Evaluations were performed at baseline and weeks $2,4,6$, and 8 . The primary outcome measures were the Aberrant Behaviour Checklist-Irritability Subscale (ABC-Irritability) score, the CGI-I score and the severity of comorbid conditions. Risperidone was titrated from 0.5 to $3 \mathrm{mg} /$ day in the first two weeks. A significant reduction of the ABC-Irritability score was observed after risperidone use. Authors reported a clinically significant improvement in ADHD and depression symptoms, as well as in global functioning.

Parmar et al. reported the case of a 15-year old boy presenting a DMDD and ADHD successfully treated with $50 \mathrm{mg}$ of naltrexone [41]. Previous treatments received were 
methylphenidate, guanfacine extended release, and aripiprazole at $5 \mathrm{mg}$ to $15 \mathrm{mg}$ once daily.

Tolerability profile was good, except for an increased sedation. The lack of evidence supporting long-term naltrexone justified the decision to stop the drug after three months. Authors described a resurgence of patient's aggressive symptoms after drug discontinuation, as well as an improvement after drug reintroduction.

\subsubsection{Ongoing studies}

Three pharmacological trials in SMD/DMDD youths are underway.

Leibenluft et al. started in November 2008 a trial to determine the feasibility and acceptability of MPH combined or not with citalopram, a selective serotonin re-uptake inhibitor (SSRI) antidepressant, in youths with SMD (NCT00794040). A wash-out period is followed by a 5-week dose stabilization phase of methylphenidate. Participants are then randomly and blindly assigned to receive citalopram (target dose: $20-40 \mathrm{mg} /$ day) or a placebo. After eight weeks subjects were invited to participate in an open treatment phase for around seven weeks. This study targets to include 160 7-17 year old youths who meet NIMH criteria for SMD. The primary outcome measures are the ABC-Irritability score and the CGI-I score. Estimated primary completion date of the study is October 2016.

In January 2013, Mc Gough et al. started a preliminary study to evaluate the feasibility and acceptability of lisdexamfetamine, a psychostimulant, combined or not with fluoxetine, a SSRI antidepressant, in youths with SMD (NCT01714310). Participants have 4 weeks open titration with lisdexamfetamine to optimal dose, followed by double-blind randomization to fluoxetine or placebo in combination with optimized lisdexamfetamine for an additional eight weeks. The investigators target to include 50 children aged $7-17$ years old meeting NIMH criteria for SMD ( $\mathrm{n}=25$, in each arm). The primary outcome is the Clinical Global Impression-Improvement-Severe Mood Dysregulation, a categorical clinician rating of overall 
improvement from baseline, modified by the NIMH to assess specific domains pertinent to

\section{DISCUSSION}

\subsection{Treatment efficacy and tolerability}

At present there is only very limited empirical evidence for interventions in SMD or DMDD youths. Behaviour therapy or CBT associated with parental training showed a potential for symptom reduction and improvement of global functioning among youths with both ADHD and SMD [36,37]. This is in line with the efficacy of parental guidance 
previously reported in youths with ADHD and behaviour problems [42]. In one study, the analyses were performed post-hoc in a subsample of the overall randomized group [36], thus calling successful randomization into question. In the second analysis, the small sizes of the sample make it difficult to prevent from generalizing to other population [37]. One pilot study shows encouraging results for the possible benefit of Interpretation Bias Therapy [13]. The rationale for the development of IBT in DMDD (also evaluated in NCT02531893) is based on the difficulties in performing specific cognitive tasks reported in this population (e.g., attentional bias to threat, poor inhibitory control) [20]. Four controlled studies are currently under way to test the effects of psychotherapeutic interventions. The benefit of DBT or IPT in DMDD (evaluated in NCT01862549, NCT01591564, NCT01962623) is hypothesised from available evidence for positive effects in youths with other internalizing disorders [43-46]. DBT, historically developed for chronically suicidal adults with borderline personality disorder, was regarded as effective to target mood dysregulation across a range of diagnoses [44]. Empirical studies support the use of DBT with adolescents diagnosed with depression [44], bipolar disorder [45] and ODD [47]. IPT is a brief psychotherapy successfully developed to target depressive symptoms in adolescents [46]. In addition to the patient's mood symptoms, focus is placed on the interpersonal context in which they occur. The greater emphasis of IPT on basic social skills and on learning to negotiate relationally could be particularly relevant to address emotional reactivity and poor tolerance to frustration in DMDD youths.

Concerning a pharmacological approach, four studies were identified [36,24,40,41]. Lithium carbonate was not found to be more effective than placebo in young inpatients with SMD [24]. However, preliminary results support a positive effect of risperidone for decreasing irritability and externalized symptoms in SMD youths [40]. A possible effect of naltrexone (one single case only) is reported in a 15-year old boy with ADHD and DMDD 
[41]. Psychostimulant was found partly effective on youths with ADHD and SMD to treat

SMD symptoms [36]. This finding is consistent with meta-analyses demonstrating an efficacy of psychostimulant on irritability [48] and in reactive aggression [49] in ADHD youths. However, in line with a prior study [32], Waxmonsky et al. [36] noted that psychostimulant remains only partially effective in this patient. In the ADHD-STP study, only $6 \%$ of youths with ADHD and SMD were in remission at endpoint, compared to $27 \%$ in the control group (ADHD without SMD) [36]. Such findings build a rationale for the development of "add-on" pharmacological strategy; i.e., the use of a second line of medication (different from psychostimulant) in youths with both ADHD and SMD/DMDD criteria. Currently, two controlled studies are under way to further clarify whether adding an SSRI antidepressant can decrease DMDD symptomatology (NCT00794040, NCT01714310). Following another pharmacological approach, one study tests the comparative efficacy of an atypical antipsychotic and a psychostimulant as a first line treatment in youths with ADHD and DMDD (NCT02063945). In particular, risperidone seems to be a promising molecule ([40], NCT02063945) in regards to its uses in the treatment of severe irritability in youths with other psychiatric disorders (e.g., autism spectrum disorder or intellectual disability) [4]. Of note, no study was conducted to test the possible benefit of selective norepinephrine reuptake inhibitors, mood stabilizers, or alpha-2 agonists, despite preliminary studies showing a possible benefit of these medications for youths with severe irritability [4].

\subsection{Limitations}

Several methodological weaknesses of the studies available for review may be partly responsible for the limited knowledge available in this field. We identified three sources that presented level II-1 evidence, one for level II-2 evidence, and three for level II-3 evidence. No 
source for level I evidence study was found. In the next paragraphs we discuss the principal limitation of these studies and suggest possible improvements.

\subsubsection{Eligibility criteria}

Criteria for DMDD have only been defined since May 2013, i.e. the publishing of the DSM-5 [6], whereas NIMH criteria for SMD have been operationalized since 2001 [34].

Consequently, the participant eligibility was based on SMD criteria in most of the reviewed studies. Results of published studies focusing on SMD youths should not be extrapolated to youths with DMDD without caution, as the two constructs are not similar. As the "hyperarousal" criterion exists for SMD but not for DMDD, treatments that are effective in decreasing hyperarousal symptoms (e.g., benzodiazepines) may be mistakenly regarded as effective for DMDD. As the profile of comorbid psychiatric disorders of SMD and DMDD can differ slightly [10] the impact of specific treatments (e.g., psychostimulant) on DMDD could be under- or overestimated if data are extrapolated from studies conducted in SMD youths. We suggest that only the DMDD category should be used in future research, and if not, detailed analysis of treatment response for each symptom should be provided.

The rate of comorbidity between DMDD and externalizing disorders was high in all studies and especially between DMDD and ADHD (ranging from 71\% to $100 \%$ ) $[24,41,40]$. As diagnostic criteria overlap between these two disorders, studies conducted in youths with both ADHD and DMDD should examine whether the improvement in DMDD symptoms is not due to the impact of the treatment on shared symptoms. Waxmonsky et al. noted that $23 \%$ of the total severity score change occurred in items overlapping with ADHD symptoms [36]. Again, item-by-tem analysis that was not performed in other studies could be useful.

This review highlights the importance of using both a measure of general improvement, such as the CGI-I, and a specific measure for symptoms severity. There are two 
reasons why the scales used to measure the main outcomes may be inappropriate. First, some of them were developed for manic symptoms (e.g., the YMRS) [36,37]; therefore, a decrease in total score may reflect a reduction in items such as loss of appetite or sleep changes which are not associated with DMDD. Second, other authors used subscores of scales that were not originally developed for irritability (e.g., the ABC-Irritability or the PANSS subscore) $[24,40]$. Content validity of such subscales is problematic as it may not cover all aspects of DMDD leading to biased results, while their poor reliability increases the risk of erroneous conclusion [50]. Moreover, as noted by Leibenluft, irritability, aggressive behaviors and hostility are embedded by distinct, even if somewhat related, pathophysiological process [51]; they therefore should be regarded as different therapeutic targets. At best, authors should use scales specifically developed to measure irritability and temper outburst such as the Affective Reactivity Index [52] or the Child Affective Lability Scale [53].

Exclusion criteria regarding intellectual disability, autism spectrum disorder and distinct manic episode were respected in line with NIMH and APA recommendations $[5,6]$. Of note, some studies included subjects with suicidal ideations (NCT01862549), whereas others did not (NCT01591564, NCT01962623). The status of medication was discussed in all except one study (NCT02531893). Authors recommend that psychotropic medication should not be used in a time period ranging from four weeks (NCT01591564) to six months [40]. At best, a period of medication withdrawal should be conducted after the period of inclusion (NCT00794040, [40]).

\subsubsection{Design}

A high level of placebo response was observed in the only placebo-controlled study [24]. This finding is consistent with the substantial decline in symptomatology scores experienced by the placebo group in RCT-DB of adolescents with mood disorders, such as 
mania $[54,55]$ or depressive disorder [56,57]. It has been noted that most of the placebo effect

in antidepressant trials occurs during the first two weeks of treatment [58], possibly due to the therapeutic effects of meeting with health professionals [56]. Interestingly, Krieger et al. observed a slight increase in the level of symptomatology at four weeks compared to it at two weeks of treatment [40]. It could be somewhat comparable to the "honey moon" observed in SMD young patients who exhibited significant improvement in symptoms after admission that have not persisted with time [36], or the rapid improvement in non-medicated youths admitted to hospitalization for severe rage episodes [14]. On the one hand, we suggest that authors examine how DMDD-symptom scores change gradually over the trial to make sure than the decline does not occur only at the very beginning of the treatment after the inclusion. On the other hand, a run-in period before randomization may be useful to distinguish a "real" pharmacological effect from the positive impact of non-specific interventions (e.g., supportive psychotherapy, cares provided by a structured milieu, or the removal from a stressful environment) [56,57], in particular when the subject is randomized just after admission in a psychiatric ward.

\subsubsection{Measures of tolerability and acceptance}

Tolerability and acceptance were systematically measured with specific scales in all pharmacological studies. Considering the fact that irritability is both a symptom of DMDD and a possible side effect of many psychotropic medications, especially SSRI [59] and stimulant [60], it may be useful to determine whether a dose-effect relationships occurs between the treatment dose or duration and the severity of side effects (as shown in [40]). Paraclinical examinations were adequately performed to examine possible metabolic side effects of atypical antipsychotic agents [40], or the effect of lithium carbonate on thyroid function [24]. 


\subsection{Clinical and research implications}

In this research we reviewed the evidence for supporting the clinical benefits of psychotherapeutic and pharmacological treatments for DMDD/SMD youths. Further research would help to clarify the mechanisms involved at different levels (psychological, cognitive or relational). As discussed in the introduction, we thought that complementary approaches are also needed, in particular exploring the positive impact of such treatments on a clinical construct such as a youth's emotional dysregulation while adopting a trans-nosological view. Severe emotional dysregulation is a key characteristic of SMD/DMDD, but it is also seen as a core symptom for other DSM-5 disorders such as trauma-related disorders (e.g., complex PTSD, reactive attachment disorder), borderline personality disorder (BPD), or intermittent explosive disorders in DSM-5.

Future research should reveal whether, and to what extent, the severely dysregulated prepubertal youths presenting SMD/DMDD criteria develop other psychiatric disorders in adolescence (especially borderline personality disorder). In turn, findings from clinical trials conducted in youths with mood dysregulation-related disorders can inform future projects for SMD/DMDD therapeutic studies. For example, antipsychotics that have shown beneficial effects in the short-term on cognitive-perceptual symptoms, anger, and mood lability in those with BPD [61] have not demonstrated effectiveness for longer use. Interestingly, psychotherapies that focus on the development of secure bounds and relational difficulties (e.g., Dialectical Behavioral Therapy or Mentalizing-Based Therapy) exhibit the highest level of evidence for youths with BPD features [62]. The interplay between the development of emotional and social abilities throughout childhood, as stressed in various theoretical models (e.g., the socio-emotional developmental model, the psychodynamic view of object relations 
theory, or the attachment theory), highlights the possible benefit of promoting the youths' social skills while caring for mood dysregulation. Surprisingly no study was devoted to the impact of family interventions in SMD/DMDD youths. The importance of parent-child quality of interactions on the emergence of child's emotion regulation strategies has however been supported in epidemiological and clinical studies (for a review [63]). Moreover, the bidirectional relationships between a child's degree of emotional distress and the parental level of adjustment has been regarded as a key mechanism to understand the persistence of symptoms [16].

\subsection{Conclusion}

The two current pharmacological strategies tested for SMD and DMDD patients are a monotherapy of psychostimulants or atypical antipsychotics and the use of SSRI as an add-on therapy in youths with comorbid ADHD and treated with psychostimulant. Psychotherapeutic treatments currently being tested are based on methods previously developed for depression (e.g., IPT, DBT) and/or youths with ADHD and behavioural problems (e.g., parental behavioural guidance). The overall level of available evidence remains dramatically poor regarding clinical needs, in particular with regards to the size of the sample studied and the heterogeneity of inclusion criteria. Moreover, the lack of follow-up above 8 weeks prevents current studies from being conclusive for the impact of treatment over a short-term duration. Future studies will further clarify the effectiveness of therapeutic interventions for DMDD individuals. Such studies should (i) be conducted in large multi-site studies, (ii) with specific and standardized procedures to measure DMDD symptom improvements, and (iii) include a run-in period to limit placebo effect. 
LIST OF ABBREVIATIONS USED: Disruptive Mood Dysregulation Disorder (DMDD);

\section{REFERENCES}

1. Masi G, Pisano S, Milone A, Muratori P (2015) Child behavior checklist dysregulation profile in children with disruptive behavior disorders: A longitudinal study. J Affect Disord 186:249-253. doi:10.1016/j.jad.2015.05.069

2. Roy AK, Lopes V, Klein RG (2014) Disruptive Mood Dysregulation Disorder: A New Diagnostic Approach to Chronic Irritability in Youth. American Journal of Psychiatry 171 (9):918-924. doi:doi:10.1176/appi.ajp.2014.13101301

3. Consoli A, Cohen D (2013) Manic-like symptoms in youths: Diagnosis issues and controversies. Neuropsychiatrie de l'Enfance et de l'Adolescence 61:154-159

4. Tourian L, LeBoeuf A, Breton JJ, Cohen D, Gignac M, Labelle R, Guile JM, Renaud J (2015) Treatment Options for the Cardinal Symptoms of Disruptive Mood Dysregulation Disorder. J Can Acad Child Adolesc Psychiatry 24 (1):41-54

5. Leibenluft E, Blair RJ, Charney DS, Pine DS (2003) Irritability in pediatric mania and other childhood psychopathology. Ann N Y Acad Sci 1008:201-218

6. American Psychiatric Association (2013) Diagnostic and Statistical Manual of Mental Disorders, 5th Edition. American Psychiatric Association,

7. Dougherty LR, Smith VC, Bufferd SJ, Carlson GA, Stringaris A, Leibenluft E, Klein DN (2014) DSM-5 disruptive mood dysregulation disorder: correlates and predictors in young children. Psychol Med 44 (11):2339-2350. doi:10.1017/\$0033291713003115

8. Copeland WE, Angold A, Costello EJ, Egger H (2013) Prevalence, comorbidity, and correlates of DSM-5 proposed disruptive mood dysregulation disorder. Am J Psychiatry 170 (2):173-179. doi:10.1176/appi.ajp.2012.12010132

9. Copeland WE, Shanahan L, Egger H, Angold A, Costello EJ (2014) Adult diagnostic and functional outcomes of DSM-5 disruptive mood dysregulation disorder. Am J Psychiatry 171 (6):668-674. doi:10.1176/appi.ajp.2014.13091213

10. Axelson D, Findling RL, Fristad MA, Kowatch RA, Youngstrom EA, Horwitz SM, Arnold LE, Frazier TW, Ryan N, Demeter C, Gill MK, Hauser-Harrington JC, Depew J, Kennedy SM, Gron BA, Rowles BM, Birmaher B (2012) Examining the proposed disruptive mood dysregulation disorder diagnosis in children in the Longitudinal Assessment of Manic Symptoms study. J Clin Psychiatry 73 (10):1342-1350. doi:10.4088/JCP.12m07674

11. Margulies DM, Weintraub S, Basile J, Grover PJ, Carlson GA (2012) Will disruptive mood dysregulation disorder reduce false diagnosis of bipolar disorder in children? Bipolar Disord 14 (5):488-496. doi:10.1111/j.1399-5618.2012.01029.x 
12. Lochman JE, Evans SC, Burke JD, Roberts MC, Fite PJ, Reed GM, de la Pena FR, Matthys W,

Ezpeleta L, Siddiqui S, Elena Garralda M (2015) An empirically based alternative to DSM-5's disruptive mood dysregulation disorder for ICD-11. World Psychiatry 14 (1):30-33.

doi:10.1002/wps.20176

13. Stoddard J, Sharif-Askary B, Harkins EA, Frank HR, Brotman MA, Penton-Voak IS, Maoz K, Bar-Haim Y, Munafo M, Pine DS, Leibenluft E (2016) An Open Pilot Study of Training Hostile Interpretation Bias to Treat Disruptive Mood Dysregulation Disorder. J Child Adolesc

Psychopharmacol 26 (1):49-57. doi:10.1089/cap.2015.0100

14. Carlson GA, Potegal M, Margulies D, Gutkovich Z, Basile J (2009) Rages--what are they and who has them? J Child Adolesc Psychopharmacol 19 (3):281-288.

doi:10.1089/cap.2008.0108

15. Moreno C, Laje G, Blanco C, Jiang H, Schmidt AB, Olfson M (2007) National trends in the outpatient diagnosis and treatment of bipolar disorder in youth. Arch Gen Psychiatry 64

(9):1032-1039. doi:10.1001/archpsyc.64.9.1032

16. Stringaris A, Taylor E (2015) Disruptive Mood: Irritability in Children and Adolescent.

17. Brotman MA, Schmajuk M, Rich BA, Dickstein DP, Guyer AE, Costello EJ, Egger HL, Angold

A, Pine DS, Leibenluft E (2006) Prevalence, clinical correlates, and longitudinal course of severe mood dysregulation in children. Biol Psychiatry 60 (9):991-997.

doi:10.1016/j.biopsych.2006.08.042

18. Stringaris A, Baroni A, Haimm C, Brotman M, Lowe CH, Myers F, Rustgi E, Wheeler W, Kayser $R$, Towbin K, Leibenluft E (2010) Pediatric bipolar disorder versus severe mood dysregulation: risk for manic episodes on follow-up. J Am Acad Child Adolesc Psychiatry 49 (4):397-405

19. Brotman MA, Kassem L, Reising MM, Guyer AE, Dickstein DP, Rich BA, Towbin KE, Pine DS, McMahon FJ, Leibenluft E (2007) Parental diagnoses in youth with narrow phenotype bipolar disorder or severe mood dysregulation. Am J Psychiatry 164 (8):1238-1241.

doi:10.1176/appi.ajp.2007.06101619

20. Guyer AE, McClure EB, Adler AD, Brotman MA, Rich BA, Kimes AS, Pine DS, Ernst M,

Leibenluft $E$ (2007) Specificity of facial expression labeling deficits in childhood

psychopathology. J Child Psychol Psychiatry 48 (9):863-871. doi:10.1111/j.1469-

7610.2007.01758.x

21. Rich BA, Carver FW, Holroyd T, Rosen HR, Mendoza JK, Cornwell BR, Fox NA, Pine DS,

Coppola R, Leibenluft E (2011) Different neural pathways to negative affect in youth with

pediatric bipolar disorder and severe mood dysregulation. J Psychiatr Res 45 (10):1283-1294.

doi:10.1016/j.jpsychires.2011.04.006

22. Dickstein DP, Gorrostieta C, Ombao H, Goldberg LD, Brazel AC, Gable CJ, Kelly C, Gee

DG, Zuo X-N, Castellanos FX, Milham MP (2010) Fronto-Temporal Spontaneous Resting State

Functional Connectivity in Pediatric Bipolar Disorder. Biological Psychiatry 68 (9):839-846.

doi:http://dx.doi.org/10.1016/j.biopsych.2010.06.029

23. Brotman MA, Rich BA, Guyer AE, Lunsford JR, Horsey SE, Reising MM, Thomas LA, Fromm SJ, Towbin K, Pine DS, Leibenluft E (2010) Amygdala activation during emotion processing of neutral faces in children with severe mood dysregulation versus ADHD or bipolar disorder. Am J Psychiatry 167 (1):61-69. doi:10.1176/appi.ajp.2009.09010043

24. Dickstein DP, Towbin KE, Van Der Veen JW, Rich BA, Brotman MA, Knopf L, Onelio L, Pine DS, Leibenluft E (2009) Randomized double-blind placebo-controlled trial of lithium in youths with severe mood dysregulation. J Child Adolesc Psychopharmacol 19 (1):61-73.

doi:10.1089/cap.2008.044

25. Comer JS, Olfson M, Mojtabai R (2010) National trends in child and adolescent

psychotropic polypharmacy in office-based practice, 1996-2007. J Am Acad Child Adolesc Psychiatry 49 (10):1001-1010. doi:10.1016/j.jaac.2010.07.007

26. Olfson M, Crystal S, Huang C, Gerhard T (2010) Trends in antipsychotic drug use by very young, privately insured children. J Am Acad Child Adolesc Psychiatry 49 (1):13-23

27. Parens E, Johnston J, Carlson GA (2010) Pediatric mental health care dysfunction disorder? The New England journal of medicine 362 (20):1853-1855.

doi:10.1056/NEJMp1003175

28. Sparks GM, Axelson DA, Yu H, Ha W, Ballester J, Diler RS, Goldstein B, Goldstein T, Hickey MB, Ladouceur CD, Monk K, Sakolsky D, Birmaher B (2014) Disruptive mood dysregulation 
disorder and chronic irritability in youth at familial risk for bipolar disorder. J Am Acad Child Adolesc Psychiatry 53 (4):408-416. doi:10.1016/j.jaac.2013.12.026

29. Efron D, Sciberras E, Anderson V, Hazell P, Ukoumunne OC, Jongeling B, Schilpzand EJ, Bisset $M$, Nicholson JM (2014) Functional status in children with ADHD at age 6-8: a controlled community study. Pediatrics 134 (4):e992-e1000. doi:10.1542/peds.2014-1027

30. Mulraney M, Schilpzand EJ, Hazell P, Nicholson JM, Anderson V, Efron D, Silk TJ, Sciberras E (2015) Comorbidity and correlates of disruptive mood dysregulation disorder in 6-8-year-old children with ADHD. Eur Child Adolesc Psychiatry. doi:10.1007/s00787-015-0738-9

31. Fernandez de la Cruz L, Simonoff E, McGough JJ, Halperin JM, Arnold LE, Stringaris A (2015) Treatment of children with attention-deficit/hyperactivity disorder (ADHD) and irritability: results from the multimodal treatment study of children with ADHD (MTA). J Am Acad Child Adolesc Psychiatry 54 (1):62-70.e63. doi:10.1016/j.jaac.2014.10.006

32. Galanter CA, Carlson GA, Jensen PS, Greenhill LL, Davies M, Li W, Chuang SZ, Elliott GR, Arnold LE, March JS, Hechtman L, Pelham WE, Swanson JM (2003) Response to methylphenidate in children with attention deficit hyperactivity disorder and manic symptoms in the multimodal treatment study of children with attention deficit hyperactivity disorder titration trial. J Child Adolesc Psychopharmacol 13 (2):123-136.

doi:10.1089/104454603322163844

33. Moher D, Liberati A, Tetzlaff J, Altman DG, Group P (2009) Preferred reporting items for systematic reviews and meta-analyses: the PRISMA statement. BMJ 339:b2535.

doi:10.1136/bmi.b2535

34. Leibenluft E (2011) Severe Mood Dysregulation, Irritability, and the Diagnostic Boundaries of Bipolar Disorder in Youths. American Journal of Psychiatry 168:129-142.

doi:10.1176/appi.ajp.2010.10050766

35. US Preventive Services Task Force (1996) Guide to clinical preventive services. In: Quality AfHRa (ed). Washington (DC),

36. Waxmonsky J, Pelham WE, Gnagy E, Cummings MR, O'Connor B, Majumdar A, Verley J, Hoffman MT, Massetti GA, Burrows-MacLean L, Fabiano GA, Waschbusch DA, Chacko A, Arnold FW, Walker KS, Garefino AC, Robb JA (2008) The efficacy and tolerability of methylphenidate and behavior modification in children with attention-deficit/hyperactivity disorder and severe mood dysregulation. J Child Adolesc Psychopharmacol 18 (6):573-588. doi:10.1089/cap.2008.065

37. Waxmonsky JG, Wymbs FA, Pariseau ME, Belin PJ, Waschbusch DA, Babocsai L, Fabiano GA, Akinnusi OO, Haak JL, Pelham WE (2013) A novel group therapy for children with ADHD and severe mood dysregulation. Journal of attention disorders 17 (6):527-541.

doi:10.1177/1087054711433423

38. Fabiano GA, Pelham WE, Gnagy EM, Burrows-MacLean L, Coles EK, Chacko A, Wymbs BT, Walker KS, Arnold F, Garefino A, Keenan JK, Onyango AN, Hoffman MT, Massetti GM, Robb JA (2007) The single and combined effects of multiple intensities of behavior modification and methylphenidate for children with attention deficit hyperactivity disorder in a classroom setting. School Psychol Rev 36 (2):195-216

39. Pelham WE, Greiner A, Gnagy EM (1997) Children's Summer Treatment Program Manual. In: Inc (ed) Comprehensive Treatment for Attention Disorders. Buffalo, NY,

40. Krieger FV, Pheula GF, Coelho R, Zeni T, Tramontina S, Zeni CP, Rohde LA (2011) An openlabel trial of risperidone in children and adolescents with severe mood dysregulation. J Child Adolesc Psychopharmacol 21 (3):237-243. doi:10.1089/cap.2010.0123

41. Parmar A, Vats D, Parmar R, Aligeti M (2014) Role of naltrexone in management of behavioral outbursts in an adolescent male diagnosed with disruptive mood dysregulation disorder. J Child Adolesc Psychopharmacol 24 (10):594-595. doi:10.1089/cap.2014.0072

42. Périsse D, Gerardin P, Cohen D, Flament M, Mazet P (2006) Conduct disorder in children and adolescents: a review of current therapeutic approaches. Neuropsychiatrie de l'enfance et de l'adolescence 54:401-410. doi:10.1016/j.neurenf.2005.09.006

43. Zhou X, Hetrick SE, Cuijpers P, Qin B, Barth J, Whittington CJ, Cohen D, Del Giovane C, Liu $Y$, Michael KD, Zhang Y, Weisz JR, Xie P (2015) Comparative efficacy and acceptability of psychotherapies for depression in children and adolescents: A systematic review and network meta-analysis. World Psychiatry 14 (2):207-222. doi:10.1002/wps.20217 
44. MacPherson HA, Cheavens JS, Fristad MA (2013) Dialectical behavior therapy for adolescents: theory, treatment adaptations, and empirical outcomes. Clinical child and family psychology review 16 (1):59-80. doi:10.1007/s10567-012-0126-7

45. Goldstein TR, Fersch-Podrat RK, Rivera M, Axelson DA, Merranko J, Yu H, Brent DA, Birmaher B (2015) Dialectical behavior therapy for adolescents with bipolar disorder: results from a pilot randomized trial. J Child Adolesc Psychopharmacol 25 (2):140-149. doi:10.1089/cap.2013.0145 46. Mufson L, Sills R (2006) Interpersonal Psychotherapy for depressed adolescents (IPT-A): an overview. Nordic journal of psychiatry 60 (6):431-437. doi:10.1080/08039480601022397

47. Nelson-Gray RO, Keane SP, Hurst RM, Mitchell JT, Warburton JB, Chok JT, Cobb AR (2006) A modified DBT skills training program for oppositional defiant adolescents: promising preliminary findings. Behav Res Ther 44 (12):181 1-1820. doi:10.1016/j.brat.2006.01.004 48. Connor DF, Glatt SJ, Lopez ID, Jackson D, Melloni RH, Jr. (2002) Psychopharmacology and aggression. I: A meta-analysis of stimulant effects on overt/covert aggression-related behaviors in ADHD. J Am Acad Child Adolesc Psychiatry 41 (3):253-261. doi:10.1097/00004583200203000-00004

49. Pappadopulos E, Woolston S, Chait A, Perkins M, Connor DF, Jensen PS (2006)

Pharmacotherapy of aggression in children and adolescents: efficacy and effect size. J Can Acad Child Adolesc Psychiatry 15 (1):27-39

50. Rust J, Golombok S (2009) Modern Psychometrics. The science of psychological assessment. 3 edn., London and New York

51. Leibenluft E, Stoddard J (2013) The developmental psychopathology of irritability. Dev Psychopathol 25 (4 Pt 2):1473-1487. doi:10.1017/s0954579413000722

52. Stringaris A, Goodman R, Ferdinando S, Razdan V, Muhrer E, Leibenluft E, Brotman MA (2012) The Affective Reactivity Index: a concise irritability scale for clinical and research settings. J Child Psychol Psychiatry 53 (11):1109-1117. doi:10.1111/j.1469-7610.2012.02561.x 53. Guile JM, Chapdelaine C, Desrosiers L, Cornez C, Bouvier H, Breton JJ (2009) Preliminary reliability study of the affective lability scale adapted for adolescents in a francophone clinical population. J Can Acad Child Adolesc Psychiatry 18 (4):293-306

54. Wagner KD, Kowatch RA, Emslie GJ, Findling RL, Wilens TE, McCague K, D'Souza J, Wamil A, Lehman RB, Berv D, Linden D (2006) A double-blind, randomized, placebo-controlled trial of oxcarbazepine in the treatment of bipolar disorder in children and adolescents. Am J Psychiatry 163 (7):1179-1186. doi:10.1176/ajp.2006.163.7.1179

55. Tohen M, Kryzhanovskaya L, Carlson G, Delbello M, Wozniak J, Kowatch R, Wagner K, Findling R, Lin D, Robertson-Plouch C, Xu W, Dittmann RW, Biederman J (2007) Olanzapine versus placebo in the treatment of adolescents with bipolar mania. Am J Psychiatry 164 (10):1547-1556. doi:10.1176/appi.ajp.2007.06111932

56. Cohen D, Consoli A, Bodeau N, Purper-Ouakil D, Deniau E, Guile JM, Donnelly C (2010) Predictors of placebo response in randomized controlled trials of psychotropic drugs for children and adolescents with internalizing disorders. J Child Adolesc Psychopharmacol 20 (1):39-47. doi:10.1089/cap.2009.0047

57. Cohen D, Deniau E, Maturana A, Tanguy ML, Bodeau N, Labelle R, Breton JJ, Guile JM (2008) Are child and adolescent responses to placebo higher in major depression than in anxiety disorders? A systematic review of placebo-controlled trials. Plos one 3 (7):e2632. doi:10.1371/journal.pone.0002632

58. Rutherford BR, Sneed JR, Tandler JM, Rindskopf D, Peterson BS, Roose SP (2011) Deconstructing pediatric depression trials: an analysis of the effects of expectancy and therapeutic contact. J Am Acad Child Adolesc Psychiatry 50 (8):782-795. doi:10.1016/j.jaac.2011.04.004

59. Henry A, Kisicki MD, Varley C (2012) Efficacy and safety of antidepressant drug treatment in children and adolescents. Mol Psychiatry 17 (12):1 186-1193. doi:10.1038/mp.2011.150 60. Efron D, Jarman F, Barker M (1997) Side effects of methylphenidate and dexamphetamine in children with attention deficit hyperactivity disorder: a double-blind, crossover trial.

Pediatrics 100 (4):662-666

61. Ingenhoven TJ, Duivenvoorden HJ (2011) Differential effectiveness of antipsychotics in borderline personality disorder: meta-analyses of placebo-controlled, randomized clinical trials on symptomatic outcome domains. Journal of clinical psychopharmacology 31 (4):489496. doi:10.1097/JCP.0b013e3182217a69 
62. Fonagy P, Speranza M, Luyten P, Kaess M, Hessels C, Bohus M (2015) ESCAP Expert Article: borderline personality disorder in adolescence: an expert research review with implications for clinical practice. Eur Child Adolesc Psychiatry 24 (1 1):1307-1320. doi:10.1007/s00787-015$0751-Z$

63. Dvir Y, Ford JD, Hill M, Frazier JA (2014) Childhood maltreatment, emotional dysregulation, and psychiatric comorbidities. Harvard review of psychiatry 22 (3):149-161.

doi:10.1097/HRP.0000000000000014 


\title{
Evidence-based treatments for youths with severely dysregulated mood: a qualitative systematic review of trials for SMD and DMDD
}

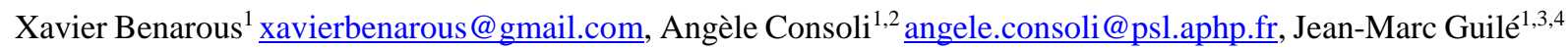 \\ guile.jean-marc@chu-amiens.fr, Sébastien Garny de La Rivière ${ }^{3}$ garnydelariviere.sebastien@chu-amiens.fr, \\ David Cohen ${ }^{1,5}$ david.cohen@psl.aphp.fr, Bertrand Olliac ${ }^{1,6}$ bertrand.olliac@gmail.com \\ ${ }^{1}$ Department of Child And Adolescent Psychiatry, Pitié-Salpêtrière Hospital, 47-83 boulevard de l'Hôpital, 75013 \\ Paris, France \\ ${ }^{2}$ INSERM U-669, PSIGIAM, Paris, France \\ ${ }^{3}$ Groupe de Recherches sur l'Analyse Multimodale de la Fonction Cérébrale, INSERM U1105, CHU, Université \\ Picardie Jules Verne, Amiens, France \\ ${ }^{4}$ Department of Psychiatry, McGill University, Montreal, Canada \\ ${ }^{5}$ CNRS UMR 7222, Institute for Intelligent Systems and Robotics-ISIR, Paris, France \\ ${ }^{6}$ Pôle Hospitalo-Universitaire de psychiatrie de l'enfant et de l'adolescent, Centre Hospitalier Esquirol, Limoges, \\ France
}

Address of correspondence: Xavier Benarous, Department of Child And Adolescent Psychiatry, Pitié-Salpêtrière Hospital, 47-83 boulevard de l'Hôpital, 75013 Paris, France

Email: xavierbenarous@gmail.com

Phone: $+33(0) 603260193$

Fax: $+33(0) 142162331$

Category: Review article

Abbreviated title: Treatments for youths with SMD and DMDD

Conflict of interest: On behalf of all authors, the corresponding author states that there is no conflict of interest. 


\begin{abstract}
The aim of this literature review was to examine the evidence for psychotherapeutic and pharmacological treatments in subjects with severely dysregulated mood and to identify potential areas for improvements in research designs. A literature search was conducted using several databases for published (PubMed, PsycINFO) and ongoing (clinical trial registries) studies conducted in youths who met NIMH's criteria for Severe Mood Dysregulation (SMD) or the DSM-5 diagnosis of Disruptive Mood Dysregulation Disorder (DMDD). Eight completed studies were identified: three randomized trials, four open pilot studies and one case report. Seven ongoing studies were found in trial registries. The available evidence suggests potential efficacy of psychotherapies which have previously been developed for internalizing and externalizing disorders. The two main pharmacological strategies tested are, first, a monotherapy of psychostimulant or atypical antipsychotic such as risperidone, already used in the treatment of severe irritability in youths with developmental disorders; and second, the use of a serotonergic antidepressant as an add-on therapy in youths treated with psychostimulant. Ongoing studies will further clarify the effectiveness of psychotherapeutic interventions for DMDD individuals and whether they should be given alone or in conjunction with other treatments. The short duration of the trials for a chronic disorder, the low number of studies, the lack of placebo or active comparator arm, and restrictive inclusion criteria in most of the controlled trials dramatically limit the interpretation of the results. Finally, future research should be conducted across multiple sites, with standardized procedures to measure DMDD symptoms reduction, and include a run-in period to limit placebo effect.
\end{abstract}

KEYWORDS: disruptive mood dysregulation disorder; severe mood dysregulation; psychotherapy; pharmacotherapy; therapeutics; irritability 


\section{INTRODUCTION}

\subsection{General background}

Children with severely dysregulated mood have become diagnostic and therapeutic challenges in-over the last two decades within the context of pediatric bipolar controversy [14]. In view of facilitating research programs researchers at the U.S. National Institute of Mental Health (NIMH) operationalized the criteria of "Severe Mood Dysregulation" (SMD), a syndrome characterized by chronic abnormal levels of anger or sadness, hyperarousal and heightened verbal or physical reactivity [5]. On the grounds of studies conducted in youths with SMD and in view of improving mental health care of youths with chronic irritability, the Disruptive Mood Dysregulation Disorder (DMDD) was introduced as a new diagnosis in the Diagnostic and Statistical Manual of Mental Disorders, fifth edition (DSM-5) within the Depressive Disorders section [6]. Youths with DMDD present chronic irritability combined with severe and recurrent episodes of temper outburst inconsistent with their developmental level at least three times per week and occurring in different settings (e.g., in family, school). These symptoms should persist more than twelve months with no symptom-free period longer than three months and with an initial onset prior to the age of 10. Prevalence of DMDD is reported to be around $8.2 \%$ in general population [7-9] and around 26-31\% in clinical settings $[10,11]$. There is much evidence supporting that DMDD symptoms severely affect a youth's'level of social functioning [7,8] and that such negative effects could persist into adulthood [9]. Copeland et al. showed that as adults youths with DMDD present a much higher level of functional impairments (i.e., adverse health outcomes, financial problems, police contact, and low educational attainment) than those with any other psychiatric disorders (e.g., depressive 
disorders, anxiety disorders, attention deficit hyperactivity disorder ADHD, disruptive disorder, or substance disorders) [9].

\subsection{Phenomenology of youths with severely dysregulated mood}

Mood dysregulation (i.e., severe irritability and high level of anger) is seen as a transdiagnostic symptom, with a dimensional continuum from its typical expression in normal development of children and adolescences to severely impairing forms in psychiatric disorders [12]. In this vein, the development of studies based on specific cognitive and emotional domains rather than DSM-5 categories of disorders has been encouraged, in particular research aligned with the framework of the Research Domain Criteria articulated by the NIMH. This strategy has led to significant improvements in our knowledge of the mechanisms underlying varying aspects of mood dysregulation in youths. Such progress may ultimately lead to discovering new markers of the disorder and targets for specific interventions. The study published by Stoddard et al. [13] provides a good example of how these different levels of analysis can be integrated in research based on a dimensional view of psychopathology; with the articulation between impaired neural substrates (i.e., orbitofrontal cortex and amygdala activation), a clinical or psychological marker (i.e., the result at a face-emotion labelling task), and a therapeutic (i.e., computer-based) intervention targeting interpretation bias).

A different approach has been used in the present review as we specifically focused on studies where the clinical categories of SMD or DMDD were applied to define the population of interest. The SMD (i.e., the research syndrome) and then DMDD (i.e., the DMS-5 diagnosis) criteria were originally developed in view of facilitating the identification of youths with severe, persistent and functionally impairing forms of irritability, who were likely to fulfil criteria for different disorders at different times (“diagnostically homeless") [14]. The development of a 


\subsection{Validity of SMD and DMDD diagnoses}

Evidence for the validity of SMD and later DMDD diagnosis was raised on the ground of studies exploring the internal and external validity of these disorders, especially data on discriminant validity [17,18], familial studies [19], psychophysiological and neuroimaging 
studies [20-23], as well as response to pharmacological treatment [24,14]. However, concerns

have been raised regarding different aspects of the diagnostic validity: the paucity of data regarding reliability in literature, the difficulty in delineating the normal and abnormal mood lability in children, and above all the high rate of overlap with others psychiatric disorders,

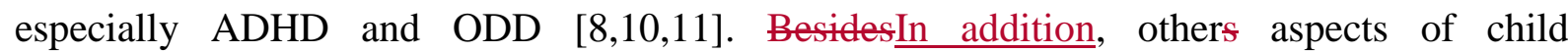
psychopathology are still rarely taken into consideration in these studies regarding some aspects of a child's individual characteristics (e.g., temperamental traits and attachment style) and environmental backgrounds (e.g., parent-child interaction patterns, possibility of co-occurring maltreatment)._Lastly, significant changes were made in the process of integrating the category of SMD in DSM-5 including removing the criterion of hyperarousal (e.g., insomnia, agitation, distractibility, racing thoughts/flight of ideas, pressured speech, and intrusiveness), and the criterion of low intelligence (IQ<80) from the exclusionary criteria, and-as well as lowering the age of onset from 12 to 10 years old [6]. Such differences are not trivial and could affect the comorbidity profiles of SMD and DMDD. For example, despite the lack of direct comparison between the two clinical entities, data suggests that DMDD most often co-occurs with depressive disorders and ODD and less with ADHD compared to SMD [10].

\subsection{Therapeutic strategies}

Little is known about effective treatments of SMD and DMDD. The DSM-5 Task Force suggested that "individual therapy, as well as work with the child's family and/or school [and] the use of medication to help address specific symptoms" could be useful for DMDD youths [6]. AlthoughHowever, the use of treatments targeting symptoms without considering the overall diagnosis has been criticized as it may contribute to the high rates of polypharmacy in this population [25-27]. Given that SMD and DMDD frequently occur with comorbid 
psychiatric disorders $[8,10,11,28-30]$, it has been suggested that therapeutic interventions

should primarily focus on treating associated disorders. However, studies examining the benefit of psychotherapy or pharmacotherapy on mood dysregulation in different psychiatric disorders are somewhat mixed [31,32]. Galanter et al. [32] found that the higher baseline levels of psychopathology of children with ADHD and mood dysregulation, compared to those without prominent mood dysregulation, persisted after intensive multimodal treatments for ADHD, suggesting the need for additional treatment. In a recent systematic review, Tourian et al. examined empirical evidence supporting the use of pharmacological treatments for severe anger/irritability symptoms in youths [4]. They found that pharmacotherapeutic treatment for both aggression and chronic irritability includes various options, such as antidepressants, especially selective norepinephrine reuptake inhibitors, mood stabilizers, psychostimulants, antipsychotics, and alpha-2 agonists. However, such findings are difficult to generalize, since, as the authors noted, a majority of the study was conducted in small and specific populations (e.g., youths with developmental disorders). Even if no treatment algorithm for severe persistent irritability in youths can be derived from this data, that study can be regarded as a first step for providing evidence-based treatments for children with DMDD as it informed about the potentially effective treatments. However, in view of meeting the needs of clinician and researcher, randomized controlled clinical trials (RCTs) that were-specifically developed for youths with SMD or DMDD are required.

The high rates of comorbidity of SMD and DMDD with externalized disorders $[8,10,11,28-30]$ raise questions about the best ways to conduct such trials. How should pharmacological and psychotherapeutic interventions for DMDD be tested within existing therapeutic strategies for externalized disorders? Which treatments should be allowed in the control group? How should the severity of mood symptoms be measured? Is the inclusion of only DMDD subjects without psychiatric comorbidity an acceptable strategy? 


\subsection{Aims of the present review}

In this study, we performed a systematic review to examine psychotherapeutic and pharmacological interventions for youths presenting SMD or DMDD. Considering the short delay since the development of DMDD's criteria, such an exhaustive review was not intended to determine the comparative efficacy and tolerability of these treatments. Our main aim was rather to describe the benefits and limitations of different research strategies currently developed for SMD and DMDD with the aim of guiding future research. In this vein, both published and ongoing studies are presented in this paper.

\section{METHODS}

\subsection{Review}

The systematic review was conducted following the recommendations outlined in the PRISMA guide (Figure 1) [33]. Titles and abstracts were scanned for relevance. Full texts were ordered in case of uncertainty to maximize sensitivity. Reference lists of retrieved systematic reviews were checked. All full texts were checked for eligibility. Any original study (open trial, double-blind trial whether randomized control or not), case-report, caseseries, meta-analysis and systematic review of pharmacological and non-pharmacological intervention was eligible for inclusion in this review. Abstracts and editorials were excluded. As DMDD was previously known in the literature under the alias of Severe Mood 
Dysregulation (SMD), -studies conducted among youths with SMD were included in the current analysis. Study participants had to be diagnosed with SMD or DMDD, and to be between five and 18 years old, or the mean age of the participants had to fall within the aforementioned age range.

[Insert Figure 1, about here]

\subsection{Search method for identification of studies}

Relevant articles for this study were obtained through Cochrane Central Register of Controlled Trials (CENTRAL), Pubmed, Medline, PsychINFO, PsychINDEXplus and Dissertation Abstracts. Each database was searched from January 2001 to December 2015. In addition, we hand searched reference lists of identified articles and pertinent reviews for additional studies. References from the reviewed articles were also screened to find more articles of interest. Furthermore, clinical trials registries (http://www.clinicaltrials.gov of the US National Institutes of Health and the WHO International Clinical Trials Registry Platform, ICTRP) were searched for ongoing trials. We used the following search terms: "Disruptive mood dysregulation disorder" OR "Severe mood dysregulation" OR “Temper outburst" AND “Therapeutics" OR “Clinical protocols" OR "Treatment” OR "Pharmacotherapy" OR "Psychotherapy". Authors independently screened potential studies, after reading the full article, for inclusion in the review, and the results were collated. The systematic review yielded 86 hits, with 29 being a duplicate; 21 hits could be excluded based on the information in the title or abstract. The full texts of 36 hits were critically reviewed leading to exclusion of another 21 articles because these were only reviews or comments and no new original data

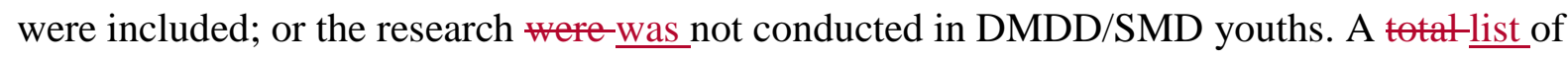


15 studies were was generated: eight completed studies (one case report, four open pilot studies and three RCTs) and seven ongoing studies found in trial registries.

\subsection{Data and analysis}

Data and information extractions from each study were performed independently by the two first authors. For each study under review, year of publication and references were extracted. In order to summarize the treatment attributes, in each report we collected the following information: description of medication, length of treatment, and dose received. Information on additional or adjunctive interventions was also collected. Additional information regarding the attributes of participants enrolled in the studies were extracted and were as follows: age, gender, how the diagnosis was made, treatment setting, comorbid conditions, sociodemographic data, and screening tools used. Although a meta-analytic review has been preferable, the diversity of statistical methods and measurement practices across studies did not allow for the calculation of pooled effect size. We categorized the level of evidence presented in each paper using the United States Preventive Services Task Force (USPSTF) criteria [35]. According to this schematic, level I evidence denotes having at least one well-designed RCT supporting a treatment's possible efficacy. Level II-1 requires a welldesigned controlled trial without randomization, level II-2 requires at least one well-designed cohort or case-control study, and level II-3 requires a multiple time series design. We excluded level III evidence (opinions of respected authorities based on clinical experience or descriptive studies) from the present review.

\section{RESULTS}




\subsection{Psychotherapeutic interventions for DMDD}

\subsubsection{Completed studies}

Only three studies were eligible for the review (Table 1): an exploratory analysis from a controlled study of multiple interventions for ADHD children [36], the subsequent open uncontrolled feasibility study conducted by the same research team on youths with ADHD and SMD [37], and an open pilot uncontrolled study on DMDD youths [13].

Waxmonsky et al. (2008) conducted secondary analysis of data from the 2003-2004 ADHD Summer Treatment Program (ADHD-STP), a research program for children aged 512 in the form of an intensive 9-week therapeutic summer camp [38]. Initial-The initial study aimed to assess the relative efficacy and synergistic effects of differential doses of behavioural and pharmacologic interventions in ADHD youths. Among the 106 participants, 33 fulfilled NIMH criteria for SMD (mean age $8.0 \pm 2.1$ years and $8.7 \pm 2.0$ years for non SMD group). The behavioral intervention consisted of daily social skills training and a reward-based learning program (detailed in [39]). This treatment varied in frequency every three weeks with the order: no behavior modification, low-intensity (i.e., weekly sessions) and high-intensity (i.e., daily sessions). Clinicians rating mood symptoms were not blind to treatments status. There was no evidence of differential treatment efficacy or tolerability on ADHD symptoms between the participants with and without SMD, even though those with SMD were more likely to remain significantly impaired at home than non-SMD subjects. After nine weeks, multimodal treatment produced a 34\% reduction in YMRS ratings in SMD subjects $(p<0.001)$.

In an open-label uncontrolled rater-blind study, Waxmonsky and colleagues examined the feasibility and preliminary efficacy of a psychotherapeutic program that integrated 
components of CBT focusing on affect regulation and parent training intervention [37]. The for SMD. All participants were male. All of the children took stimulant medication for ADHD and all but two participants were currently receiving counselling services. SMD symptoms were assessed using the depression and mania modules from the Washington University Kiddie Schedule for Affective Disorders and Schizophrenia (WASH-U-KSADS). The sessions consisted of 105-minute concurrent parent and child meetings. Six of the seven (86\%)-families $(86 \%)$ completed at least seven of the nine weeks in the program. Over the 16 week follow-up, participants showed a reduction in the level of depressive symptoms (CDRS$\mathrm{R}, d=1.17$ ) and externalizing symptoms (ADHD: $d=0.30$; ODD: $d=0.26$; CD: $d=0.27$ ). Authors interpreted the reduction in YMRS score $(d=0.81)$ as an improvement in mood lability among participants.

In an open-label uncontrolled study, Stoddard and colleagues examined the preliminary efficacy of an intervention based on four session of computer-based Hostile Interpretation Therapy [13]. The 14 included children (mean age $14.1 \pm 2.4$ years) whe presented DMDD. The gender ratio was 8:6 for female. DMDD symptoms were assessed using the Affective Reactivity Index and the Clinical Global Impression- Improvement scale. Training is designed to shift interpretation of ambiguous morphs bias toward happy judgments. Ten subjects completed an implicit functional MRI face-emotion processing task. Active training is associated with a shift in balance point toward more happy judgments (use as a proxy for hostile attribution bias) ( $\beta=2.25$ morphs). Evidence suggests that active training may be associated with decreased irritability ( $\beta=-1.57$ in parent-report ARI score, no significant change in self-report) and changes in activation patterns in the lateral orbitofrontal cortex. 


\subsubsection{Ongoing studies}

Four trials were found searching the clinical trials registries that are underway.

The group from Yale University started a randomized open-label controlled study in May 2013 to examine feasibility and preliminary efficacy of Dialectical Behaviour Therapy adapted to children (DBT-C) (NCT01862549). The study targets to include 60 7-12 years old children meeting DSM-5 criteria for DMDD. Participants are randomly assigned to receive one of two treatments for 30 weeks: DBT-C or enhanced care (active control condition). Participants on the DBT-C arm received two pre-treatment sessions and 24 treatment sessions with once per week meetings, including $30 \mathrm{~min}$ individual child therapy, 20 min meeting with a caregiver and 40 min of skills training with both. Enhanced care consists of supportive individual psychotherapy, such as cognitive behavioural skills training and adjunctive family interventions (e.g., parenting skills training, structuring household environment, and safety planning). After the acute 32-week intervention period, 3-month follow-up assessments are conducted. The primary outcome is the attendance and drop-out rate measure, the level of satisfaction and compliance at 32 weeks; secondary end-points are reduction in DMDD symptoms and disruptive problems, psychosocial functioning and mental health service use. Estimated primary completion date of the study is July 2015.

The second ongoing study investigates the feasibility and acceptability of Interpersonal Psychotherapy for youths with SMD (IPT-SMD). A monocentric uncontrolled open-label study (NCT01591564) started in May 2012 and targeted to include five subjects who meet NIMH criteria for SMD. Youth receive weekly therapy sessions for 16 weeks and then bi-weekly sessions until week 20. Parent sessions are also included. The primary outcome is the retention rate and secondary end-points include various measures of clinical improvement. The investigators hypothesized that retention rates will be above $80 \%$ and the 
satisfaction score above six on a seven point scale. Although the results of this research have study in October 2013 to test the effectiveness of Interpersonal Psychotherapy for Youth with Mood and Behaviour Dysregulation (IPT-MBD) on a more important sample size and allow for a longer follow-up time (NCT01962623). IPT-MBD is nearly identical to IPT-SMS, except that bi-weekly sessions last until week 24 . This study targets to include 44 youths between 13 and 17 years meeting criteria for SMD. Primary and secondary outcomes are similar to prior research. Estimated primary completion date of the study is August 2016.

A monocentric open-label uncontrolled study is underway since August 2015 to compare the efficacy of CBT and Interpretation Bias Training (IBT) on DMDD (NCT02531893). IBT is a newly developed computer-based training focusing on the socioemotional information process impairments described in youths with severe irritability (e.g., anger attribution bias). IBT is performed during 14 sessions over 10 weeks (four sessions in four days, followed by eight weekly booster sessions after a two weeks delay) and CBT consists of 12-16 weekly meetings. Primary outcomes are improvement in the Clinical Global Impressions-Improvement score (CGI-I) and changes in irritability score using the Affective Reactivity Index (ARI). A four-week wash-out period is planned for those who participate in both treatments. Estimated primary completion date of the study is August 2019. [Insert Table 1 about here]

\subsection{Pharmacological treatments for DMDD}

\subsubsection{Completed studies}

Only four completed pharmacological eempleted-studies were eligible for the review (Table 1). 
In the secondary analysis of data from the 2003-2004 ADHD Summer Treatment

Program, Waxmonsky et al. examined the effectiveness of different doses of methylphenidate (MPH) in SMD symptoms in children aged 5-12 with ADHD [36]. All subjects in each psychotherapeutic group were treated with increasing MPH doses (placebo, $0.15 \mathrm{mg} / \mathrm{kg}, 0.3$ $\mathrm{mg} / \mathrm{kg}$, and $0.6 \mathrm{mg} / \mathrm{kg}$ ). As mentioned above, multimodal treatment produced a $34 \%$ reduction in YMRS ratings in SMD subjects.

Dickstein et al. led a placebo-controlled randomized trial to test the efficacy of lithium in SMD [24]. At admission 7-17 year old youths with SMD were tapered off previously prescribed medication. Those who continued to meet SMD criteria after a 2-week, singleblind, placebo run-in were randomized to a 6-week double-blind trial of either lithium $(n=14)$ or placebo $(n=11)$. The primary outcome measure was the CGI-I score less than four at trial's end. Magnetic resonance spectroscopy (MRS) was performed in all participants to measure biological markers known to be associated with lithium activity (i.e., myoinositol, $\mathrm{N}$-acetylaspartate and combined glutamate). Almost half of the subjects $(n=20)$ were not randomized due to significant clinical improvement during the placebo run-in. Among randomized patients, there were no significant between-group differences in either clinical or MRS outcome measures.

Krieger et al. conducted an open-label trial to determine the effectiveness of risperidone on youths with DMDD [40]. Of the 97 subjects initially assessed for severe irritability symptoms only 21 met DMDD criteria and were finally enrolled in the study. Evaluations were performed at baseline and weeks 2, 4, 6, and 8. The primary outcome measures were the Aberrant Behaviour Checklist-Irritability Subscale (ABC-Irritability) score, the CGI-I score and the severity of comorbid conditions. Risperidone was titrated from 0.5 to $3 \mathrm{mg} /$ day in the first two weeks. A significant reduction of the ABC-Irritability score 
was observed after risperidone use. Authors reported a clinically significant improvement in ADHD and depression symptoms, as well as in global functioning.

Parmar et al. reported the case of a 15-year old boy presenting a DMDD and ADHD successfully treated with $50 \mathrm{mg}$ of naltrexone [41]. Previous treatments received were methylphenidate, guanfacine extended release, and aripiprazole at $5 \mathrm{mg}$ to $15 \mathrm{mg}$ once daily. Tolerability profile was good, except for an increased sedation. The lack of evidence supporting long-term naltrexone justified the decision to stop the drug after three months. Authors described a resurgence of patient's aggressive symptoms after drug discontinuation, as well as an improvement after drug reintroduction.

\subsubsection{Ongoing studies}

Three pharmacological trials in SMD/DMDD youths are underway.

Leibenluft et al. started in November 2008 a trial to determine the feasibility and acceptability of MPH combined or not with citalopram, a selective serotonin re-uptake inhibitor (SSRI) antidepressant, in youths with SMD (NCT00794040). A wash-out period is followed by a 5-week dose stabilization phase of methylphenidate. Participants are then randomly and blindly assigned to receive citalopram (target dose: $20-40 \mathrm{mg} /$ day) or a placebo. After eight weeks subjects were invited to participate in an open treatment phase for around seven weeks. This study targets to include 160 7-17 year old youths who meet NIMH criteria for SMD. The primary outcome measures are the ABC-Irritability score and the CGI-I score. Estimated primary completion date of the study is October 2016.

In January 2013, Mc Gough et al. started a preliminary study to evaluate the feasibility and acceptability of lisdexamfetamine, a psychostimulant, combined or not with fluoxetine, a SSRI antidepressant, in youths with SMD (NCT01714310). Participants have 4 weeks open titration with lisdexamfetamine to optimal dose, followed by double-blind randomization 
to fluoxetine or placebo in combination with optimized lisdexamfetamine for an additional

\title{
4. DISCUSSION
}

[Insert Table 3, about here] eight weeks. The investigators target to include 50 children aged $7-17$ years old meeting NIMH criteria for SMD ( $\mathrm{n}=25$, in each arm). The primary outcome is the Clinical Global Impression-Improvement-Severe Mood Dysregulation, a categorical clinician rating of overall improvement from baseline, modified by the NIMH to assess specific domains pertinent to SMD symptoms; secondary end-points are improvement in anxiety and mood symptoms, emotion regulation and disruptive problems, changes on EEG profiles of cortical activity from baseline at week 12. Estimated primary completion date of the study is July 2015.

Gothelf et al. are conducting an ongoing trial since February 2014 in view of comparing the feasibility and acceptability of MPH vs. risperidone in the treatment of youths with both ADHD and DMDD (NCT02063945). Participants are randomly assigned to one of the two arms. The primary outcome measure is the reduction of aggressive behaviour (measured with the Retrospective Modified Overt Aggression Scale) after an 8-week treatment. This study targets to include 70 youths (5-18 year old) who meet DSM-5 criteria for both DMDD and ADHD. Estimated primary completion date of the study is February 2016.

[Insert Table 2, about here]

\author{
4.1.Treatment efficacy and tolerability \\ 4. DISCUSSION
}


At present there is only very limited empirical evidence for interventions in SMD or

DMDD youths. Behaviour therapy or CBT associated with parental training showed a potential for symptom reduction and improvement of global functioning among youths with both ADHD and SMD [36,37]. This is in line with the efficacy of parental guidance previously reported in youths with ADHD and behaviour problems [42]. In one study, the analyses were performed post-hoc in a subsample of the overall randomized group [36], thus calling successful randomization into question. In the second analysis, the small sizes of the sample make it difficult to prevent from generalizing to other population [37]. One pilot study shows encouraging results for the possible benefit of Interpretation Bias Therapy [13]. The rationale for the development of IBT in DMDD (also evaluated in NCT02531893) is based on the difficulties in performing specific cognitive tasks reported in this population (e.g., attentional bias to threat, poor inhibitory control) [20]. Four controlled studies are currently under way to test the effects of psychotherapeutic interventions. The benefit of DBT or IPT in DMDD (evaluated in NCT01862549, NCT01591564, NCT01962623) is hypothesised from available evidence for positive effects in youths with other internalizing disorders [43-46]. DBT, historically developed for chronically suicidal adults with borderline personality disorder, was regarded as effective to target mood dysregulation across a range of diagnoses [44]. Empirical studies support the use of DBT with adolescents diagnosed with depression [44], bipolar disorder [45] and ODD [47]. IPT is a brief psychotherapy successfully developed to target depressive symptoms in adolescents [46]. In addition to the patient's mood symptoms, focus is placed on the interpersonal context in which they occur. The greater emphasis of IPT on basic social skills and on learning to negotiate relationally could be particularly relevant to address emotional reactivity and poor tolerance to frustration in DMDD youths. 
Concerning a pharmacological approach, four studies were identified [36,24,40,41].

Lithium carbonate was not found to be more effective than placebo in young inpatients with SMD [24]. However, preliminary results support a positive effect of risperidone for decreasing irritability and externalized symptoms in SMD youths [40]. A possible effect of naltrexone (one single case only) is reported in a 15-year old boy with ADHD and DMDD [41]. Psychostimulant was found partly effective on youths with ADHD and SMD to treat SMD symptoms [36]. This finding is consistent with meta-analyses demonstrating an efficacy of psychostimulant on irritability [48] and in reactive aggression [49] in ADHD youths. However, in line with a prior study [32], Waxmonsky et al. [36] noted that psychostimulant remains only partially effective in this patient. In the ADHD-STP study, only $6 \%$ of youths with ADHD and SMD were in remission at endpoint, compared to $27 \%$ in the control group (ADHD without SMD) [36]. Such findings build a rationale for the development of "add-on" pharmacological strategy; i.e., the use of a second line of medication (different from psychostimulant) in youths with both ADHD and SMD/DMDD criteria. Currently, two controlled studies are under way to further clarify whether adding an SSRI antidepressant can decrease DMDD symptomatology (NCT00794040, NCT01714310). Following another pharmacological approach, one study tests the comparative efficacy of an atypical antipsychotic and a psychostimulant as a first line treatment in youths with ADHD and DMDD (NCT02063945). In particular, risperidone seems to be a promising molecule ([40], NCT02063945) in regards to its uses in the treatment of severe irritability in youths with other psychiatric disorders (e.g., autism spectrum disorder or intellectual disability) [4]. Of note, no study was conducted to test the possible benefit of selective norepinephrine reuptake inhibitors, mood stabilizers, or alpha-2 agonists, despite preliminary studies showing a possible benefit of these medications for youths with severe irritability [4]. 


\subsection{Limitations}

Several methodological weaknesses of the studies available for review may be partly responsible for the limited knowledge available in this field. We identified three sources that presented level II-1 evidence, one for level II-2 evidence, and three for level II-3 evidence. No source for level I evidence study were-was found. In the next paragraphs we discuss the principal limitation of these studies and suggest possible improvements.

\subsubsection{Eligibility criteria}

Criteria for DMDD have only been defined since May 2013, i.e. the publishing of the DSM-5 [6], whereas NIMH criteria for SMD have been operationalized since 2001 [34]. Consequently, the participant eligibility was based on SMD criteria in most of the reviewed studies. Results of published studies focusing on SMD youths should not be extrapolated to youths with DMDD without caution, as the two constructs are not similar. As the "hyperarousal" criterion exists for SMD but not for DMDD, treatments that are effective in decreasing hyperarousal symptoms (e.g., benzodiazepines) may be mistakenly regarded as effective for DMDD. As the profile of comorbid psychiatric disorders of SMD and DMDD can differ slightly [10] the impact of specific treatments (e.g., psychostimulant) on DMDD could be under- or overestimated if data are extrapolated from studies conducted in SMD youths. We suggest that only the DMDD category should be used in future research, and if not $_{2}$ detailed analysis of treatment response for each symptom should be provided.

The rate of comorbidity between DMDD and externalizing disorders were-was high in all studies and especially between DMDD and ADHD (ranging from $71 \%$ to $100 \%$ ) $[24,41,40]$. As diagnostic criteria overlap between these two disorders, studies conducted in youths with both ADHD and DMDD should examine whether the improvement in DMDD 
symptoms is not due to the impact of the treatment on shared symptoms. Waxmonsky et al. noted that $23 \%$ of the total severity score change occurred in items overlapping with ADHD symptoms [36]. Again, item-by-tem analysis that was not performed in other studies could be useful.

This review highlights the importance of using both a measure of general improvement, such as the CGI-I, and a specific measure for symptoms severity. There are two reasons why the scales used to measure the main outcomes may be inappropriate. First, some of them were developed for manic symptoms (e.g., the YMRS) [36,37]; therefore, a decrease in total score may reflect a reduction in items such as loss of appetite or sleep changes which are not associated with DMDD. Second, other authors used subscores of scales that were not originally developed for irritability (e.g., the ABC-Irritability or the PANSS subscore) $[24,40]$. Content validity of such subscales is problematic as it may not cover all aspects of DMDD leading to biased results, while their poor reliability increases the risk of erroneous conclusion [50]. Moreover, as noted by Leibenluft, irritability, aggressive behaviors and hostility are embedded by distinct, even if somewhat related, pathophysiological process [51]; and-they therefore should be regarded as different therapeutic targets. At best, authors should use scales specifically developed to measure irritability and temper outburst such as the Affective Reactivity Index [52] or the Child Affective Lability Scale [53].

Exclusion criteria regarding intellectual disability, autism spectrum disorder and distinct manic episode were respected in line with NIMH and APA recommendations $[5,6]$. Of note, some studies included subjects with suicidal ideations (NCT01862549), whereas others did not (NCT01591564, NCT01962623). The status of medication was discussed in all except one study (NCT02531893). Authors recommend that psychotropic medication should not be used in a time period ranging from four weeks (NCT01591564) to six months [40]. At 
best, a period of medication withdrawal should be conducted after the period of inclusion (NCT00794040, [40]).

\subsubsection{Design}

A high level of placebo response was observed in the only placebo-controlled study [24]. This finding is consistent with the substantial decline in symptomatology scores experienced by the placebo group in RCT-DB of adolescents with mood disorders, such as mania $[54,55]$ or depressive disorder $[56,57]$. It has been noted that most of the placebo effect in antidepressant trials occurs during the first two weeks of treatment [58], possibly due to the therapeutic effects of meeting with health professionals [56]. Interestingly, Krieger et al. observed a slight increase in the level of symptomatology at four weeks compared to it at two weeks of treatment [40]. It could be somewhat comparable to the "honey moon" observed in SMD young patients who exhibited significant improvement in symptoms after admission that have not persisted with time [36], or the rapid improvement in non-medicated youths admitted in-to hospitalization for severe rage episodes [14]. On the one hand, we suggest that authors examine how DMDD-symptom scores change gradually over the trial- to make sure than the decline does not occur only at the very beginning of the treatment after the inclusion. On the other hand, a run-in period before randomization may be useful to distinguish a "real" pharmacological effect from the positive impact of non-specific interventions (e.g., supportive psychotherapy, cares provided by a structured milieu, or the removal from a stressful environment) [56,57], in particular when the subject is randomized just after admission in a psychiatric ward.

\subsubsection{Measures of tolerability and acceptance}


Tolerability and acceptance were systematically measured with specific scales in all pharmacological studies. Considering the fact that irritability is both a symptom of DMDD and a possible side effect of many psychotropic medications, especially SSRI [59] and stimulant [60], it may be useful to determine whether a dose-effect relationships occurs between the treatment dose or duration and the severity of side effects (as shown in [40]). Paraclinical examinations were adequately performed to examine possible metabolic side effects of atypical antipsychotic agents [40], or the effect of lithium carbonate on thyroid function [24].

\subsection{Clinical and research implications}

In this research we reviewed the evidence for supporting the clinical benefits of psychotherapeutic and pharmacological treatments for DMDD/SMD youths. Further research would help to clarify the mechanisms involved at different levels (psychological, cognitive or relational). As discussed in the introduction, we thought that complementary approaches are also needed, in particular exploring the positive impact of such treatments on a clinical construct such as a youth's emotional dysregulation while adopting a trans-nosological view. Severe emotional dysregulation is a key characteristic of SMD/DMDD, but it is also seen as a core symptom for other DSM-5 disorders, such as trauma-related disorders (e.g., complex PTSD, reactive attachment disorder), borderline personality disorder (BPD), or intermittent explosive disorders in DSM-5.

Future research should reveal whether, and to what extent, the severely dysregulated prepubertal youths presenting SMD/DMDD criteria develop other psychiatric disorders in adolescence (especially borderline personality disorder). In turn, findings from clinical trials conducted in youths with mood dysregulation-related disorders can inform future projects for 
SMD/DMDD therapeutic studies. For example, antipsychotics that have shown beneficial

\subsection{Conclusion}

The two current pharmacological strategies tested for SMD and DMDD patients are a monotherapy of psychostimulants or atypical antipsychotics and the use of SSRI as an add-on therapy in youths with comorbid ADHD and treated with psychostimulant. Psychotherapeutic treatments currently being tested are based on methods previously developed for depression (e.g., IPT, DBT) and/or youths with ADHD and behavioural problems (e.g., parental behavioural guidance). The overall level of available evidence remains dramatically poor 
regarding clinical needs, in particular with regards to the size of the sample studied and the heterogeneity of inclusion criteria. Moreover, the lack of follow-up above 8 weeks prevents current studies from being conclusive for the impact of treatment over a short-term duration. Future studies will further clarify the effectiveness of therapeutic interventions for DMDD individuals. Such studies should (i) be conducted in large multi-site studies, (ii) with specific and standardized procedures to measure DMDD symptom improvements, and (iii) include a run-in period to limit placebo effect.

LIST OF ABBREVIATIONS USED: Disruptive Mood Dysregulation Disorder (DMDD); Severe Mood Dysregulation (SMD); Attention Deficit with Hyperactivity Disorder (ADHD); Oppositional Defiant Disorder (ODD); Conduct Disorder (CD); Separation Anxiety Disorder (SAD); Anxiety Disorders (AD); Major Depressive Disorder (MDD); National Institute of Mental Health (NIMH); Cognitive Behavioral Therapy (CBT); Behavioral Parental Training (BPT); Disruptive Behavior Disorders Interview (DBD); Washington University Kiddie Schedule for Affective Disorders and Schizophrenia (WASH-U-KSADS); Clinical Global Impressions-Improvement (CGI-I); Clinical Global Impressions-Severity (CGI-S)

\section{REFERENCES}

1. Masi G, Pisano S, Milone A, Muratori P (2015) Child behavior checklist dysregulation profile in children with disruptive behavior disorders: A longitudinal study. J Affect Disord 186:249-253. doi:10.1016/j.jad.2015.05.069

2. Roy AK, Lopes V, Klein RG (2014) Disruptive Mood Dysregulation Disorder: A New Diagnostic Approach to Chronic Irritability in Youth. American Journal of Psychiatry 171 (9):918-924. doi:doi:10.1176/appi.ajp.2014.13101301

3. Consoli A, Cohen D (2013) Manic-like symptoms in youths: Diagnosis issues and controversies. Neuropsychiatrie de l'Enfance et de l'Adolescence 61:154-159 4. Tourian L, LeBoeuf A, Breton JJ, Cohen D, Gignac M, Labelle R, Guile JM, Renaud J (2015) Treatment Options for the Cardinal Symptoms of Disruptive Mood Dysregulation Disorder. J Can Acad Child Adolesc Psychiatry 24 (1):41-54 
6. American Psychiatric Association (2013) Diagnostic and Statistical Manual of Mental Disorders, 5th Edition. American Psychiatric Association,

7. Dougherty LR, Smith VC, Bufferd SJ, Carlson GA, Stringaris A, Leibenluft E, Klein DN (2014) DSM-5 disruptive mood dysregulation disorder: correlates and predictors in young children. Psychol Med 44 (11):2339-2350. doi:10.1017/S0033291713003115

8. Copeland WE, Angold A, Costello EJ, Egger H (2013) Prevalence, comorbidity, and correlates of DSM-5 proposed disruptive mood dysregulation disorder. Am J Psychiatry 170 (2):173-179. doi:10.1176/appi.ajp.2012.12010132

9. Copeland WE, Shanahan L, Egger H, Angold A, Costello EJ (2014) Adult diagnostic and functional outcomes of DSM-5 disruptive mood dysregulation disorder. Am J Psychiatry 171 (6):668-674. doi:10.1176/appi.ajp.2014.13091213

10. Axelson D, Findling RL, Fristad MA, Kowatch RA, Youngstrom EA, Horwitz SM, Arnold LE, Frazier TW, Ryan N, Demeter C, Gill MK, Hauser-Harrington JC, Depew J, Kennedy SM, Gron BA, Rowles BM, Birmaher B (2012) Examining the proposed disruptive mood dysregulation disorder diagnosis in children in the Longitudinal Assessment of Manic Symptoms study. J Clin Psychiatry 73 (10):1342-1350. doi:10.4088/JCP.12m07674

11. Margulies DM, Weintraub S, Basile J, Grover PJ, Carlson GA (2012) Will disruptive mood dysregulation disorder reduce false diagnosis of bipolar disorder in children? Bipolar Disord 14 (5):488-496. doi:10.1111/j.1399-5618.2012.01029.x

12. Lochman JE, Evans SC, Burke JD, Roberts MC, Fite PJ, Reed GM, de la Pena FR, Matthys W, Ezpeleta L, Siddiqui S, Elena Garralda M (2015) An empirically based alternative to DSM-5's disruptive mood dysregulation disorder for ICD-11. World Psychiatry 14 (1):30-33.

doi:10.1002/wps.20176

13. Stoddard J, Sharif-Askary B, Harkins EA, Frank HR, Brotman MA, Penton-Voak IS, Maoz K, Bar-Haim Y, Munafo M, Pine DS, Leibenluft E (2016) An Open Pilot Study of Training Hostile Interpretation Bias to Treat Disruptive Mood Dysregulation Disorder. J Child Adolesc Psychopharmacol 26 (1):49-57. doi:10.1089/cap.2015.0100

14. Carlson GA, Potegal M, Margulies D, Gutkovich Z, Basile J (2009) Rages--what are they and who has them? J Child Adolesc Psychopharmacol 19 (3):281-288.

doi:10.1089/cap.2008.0108

15. Moreno C, Laje G, Blanco C, Jiang H, Schmidt AB, Olfson M (2007) National trends in the outpatient diagnosis and treatment of bipolar disorder in youth. Arch Gen Psychiatry 64 (9):1032-1039. doi:10.1001/archpsyc.64.9.1032

16. Stringaris A, Taylor E (2015) Disruptive Mood: Irritability in Children and Adolescent.

17. Brotman MA, Schmajuk M, Rich BA, Dickstein DP, Guyer AE, Costello EJ, Egger HL, Angold A, Pine DS, Leibenluft E (2006) Prevalence, clinical correlates, and longitudinal course of severe mood dysregulation in children. Biol Psychiatry 60 (9):991-997.

doi:10.1016/j.biopsych.2006.08.042

18. Stringaris A, Baroni A, Haimm C, Brotman M, Lowe CH, Myers F, Rustgi E, Wheeler W, Kayser R, Towbin K, Leibenluft E (2010) Pediatric bipolar disorder versus severe mood dysregulation: risk for manic episodes on follow-up. J Am Acad Child Adolesc Psychiatry 49 (4):397-405 19. Brotman MA, Kassem L, Reising MM, Guyer AE, Dickstein DP, Rich BA, Towbin KE, Pine DS, McMahon FJ, Leibenluft E (2007) Parental diagnoses in youth with narrow phenotype bipolar disorder or severe mood dysregulation. Am J Psychiatry 164 (8):1238-1241.

doi:10.1176/appi.ajp.2007.06101619

20. Guyer AE, McClure EB, Adler AD, Brotman MA, Rich BA, Kimes AS, Pine DS, Ernst M, Leibenluft $E$ (2007) Specificity of facial expression labeling deficits in childhood psychopathology. J Child Psychol Psychiatry 48 (9):863-871. doi:10.1111/j.14697610.2007.01758.x

21. Rich BA, Carver FW, Holroyd T, Rosen HR, Mendoza JK, Cornwell BR, Fox NA, Pine DS, Coppola R, Leibenluft E (2011) Different neural pathways to negative affect in youth with pediatric bipolar disorder and severe mood dysregulation. J Psychiatr Res 45 (10):1283-1294. doi:10.1016/j.jpsychires.2011.04.006

22. Dickstein DP, Gorrostieta C, Ombao H, Goldberg LD, Brazel AC, Gable CJ, Kelly C, Gee DG, Zuo X-N, Castellanos FX, Milham MP (2010) Fronto-Temporal Spontaneous Resting State Functional Connectivity in Pediatric Bipolar Disorder. Biological Psychiatry 68 (9):839-846.

doi:http://dx.doi.org/10.1016/j.biopsych.2010.06.029 
23. Brotman MA, Rich BA, Guyer AE, Lunsford JR, Horsey SE, Reising MM, Thomas LA, Fromm SJ, Towbin K, Pine DS, Leibenluft E (2010) Amygdala activation during emotion processing of neutral faces in children with severe mood dysregulation versus ADHD or bipolar disorder. Am J Psychiatry 167 (1):61-69. doi:10.1176/appi.ajp.2009.09010043

24. Dickstein DP, Towbin KE, Van Der Veen JW, Rich BA, Brotman MA, Knopf L, Onelio L, Pine DS, Leibenluft E (2009) Randomized double-blind placebo-controlled trial of lithium in youths with severe mood dysregulation. J Child Adolesc Psychopharmacol 19 (1):61-73.

doi:10.1089/cap.2008.044

25. Comer JS, Olfson M, Mojtabai R (2010) National trends in child and adolescent psychotropic polypharmacy in office-based practice, 1996-2007. J Am Acad Child Adolesc Psychiatry 49 (10):1001-1010. doi:10.1016/j.jaac.2010.07.007

26. Olfson M, Crystal S, Huang C, Gerhard T (2010) Trends in antipsychotic drug use by very young, privately insured children. J Am Acad Child Adolesc Psychiatry 49 (1):13-23 27. Parens E, Johnston J, Carlson GA (2010) Pediatric mental health care dysfunction disorder? The New England journal of medicine 362 (20):1853-1855.

doi:10.1056/NEJMP1003175

28. Sparks GM, Axelson DA, Yu H, Ha W, Ballester J, Diler RS, Goldstein B, Goldstein T, Hickey MB, Ladouceur CD, Monk K, Sakolsky D, Birmaher B (2014) Disruptive mood dysregulation disorder and chronic irritability in youth at familial risk for bipolar disorder. J Am Acad Child Adolesc Psychiatry 53 (4):408-416. doi:10.1016/j.jaac.2013.12.026

29. Efron D, Sciberras E, Anderson V, Hazell P, Ukoumunne OC, Jongeling B, Schilpzand EJ, Bisset M, Nicholson JM (2014) Functional status in children with ADHD at age 6-8: a controlled community study. Pediatrics 134 (4):e992-e1000. doi:10.1542/peds.2014-1027

30. Mulraney M, Schilpzand EJ, Hazell P, Nicholson JM, Anderson V, Efron D, Silk TJ, Sciberras E (2015) Comorbidity and correlates of disruptive mood dysregulation disorder in 6-8-year-old children with ADHD. Eur Child Adolesc Psychiatry. doi:10.1007/s00787-015-0738-9

31. Fernandez de la Cruz L, Simonoff E, MCGough JJ, Halperin JM, Arnold LE, Stringaris A (2015) Treatment of children with attention-deficit/hyperactivity disorder (ADHD) and irritability: results from the multimodal treatment study of children with ADHD (MTA). J Am Acad Child Adolesc Psychiatry 54 (1):62-70.e63. doi:10.1016/j.jaac.2014.10.006

32. Galanter CA, Carlson GA, Jensen PS, Greenhill LL, Davies M, Li W, Chuang SZ, Elliott GR, Arnold LE, March JS, Hechtman L, Pelham WE, Swanson JM (2003) Response to methylphenidate in children with attention deficit hyperactivity disorder and manic symptoms in the multimodal treatment study of children with attention deficit hyperactivity disorder titration trial. J Child Adolesc Psychopharmacol 13 (2):123-136.

doi:10.1089/104454603322163844

33. Moher D, Liberati A, Tetzlaff J, Altman DG, Group P (2009) Preferred reporting items for systematic reviews and meta-analyses: the PRISMA statement. BMJ 339:b2535.

doi:10.1136/bmj.b2535

34. Leibenluft E (2011) Severe Mood Dysregulation, Irritability, and the Diagnostic Boundaries of Bipolar Disorder in Youths. American Journal of Psychiatry 168:129-142.

doi:10.1176/appi.ajp.2010.10050766

35. US Preventive Services Task Force (1996) Guide to clinical preventive services. In: Quality AfHRa (ed). Washington (DC),

36. Waxmonsky J, Pelham WE, Gnagy E, Cummings MR, O'Connor B, Majumdar A, Verley J, Hoffman MT, Massetti GA, Burrows-MacLean L, Fabiano GA, Waschbusch DA, Chacko A, Arnold FW, Walker KS, Garefino AC, Robb JA (2008) The efficacy and tolerability of methylphenidate and behavior modification in children with attention-deficit/hyperactivity disorder and severe mood dysregulation. J Child Adolesc Psychopharmacol 18 (6):573-588. doi:10.1089/cap.2008.065

37. Waxmonsky JG, Wymbs FA, Pariseau ME, Belin PJ, Waschbusch DA, Babocsai L, Fabiano GA, Akinnusi OO, Haak JL, Pelham WE (2013) A novel group therapy for children with ADHD and severe mood dysregulation. Journal of attention disorders 17 (6):527-541.

doi:10.1177/1087054711433423

38. Fabiano GA, Pelham WE, Gnagy EM, Burrows-MacLean L, Coles EK, Chacko A, Wymbs BT, Walker KS, Arnold F, Garefino A, Keenan JK, Onyango AN, Hoffman MT, Massetti GM, Robb JA (2007) The single and combined effects of multiple intensities of behavior modification and 
methylphenidate for children with attention deficit hyperactivity disorder in a classroom setting. School Psychol Rev 36 (2):195-216

39. Pelham WE, Greiner A, Gnagy EM (1997) Children's Summer Treatment Program Manual. In: Inc (ed) Comprehensive Treatment for Attention Disorders. Buffalo, NY,

40. Krieger FV, Pheula GF, Coelho R, Zeni T, Tramontina S, Zeni CP, Rohde LA (2011) An openlabel trial of risperidone in children and adolescents with severe mood dysregulation. J Child Adolesc Psychopharmacol 21 (3):237-243. doi:10.1089/cap.2010.0123

41. Parmar A, Vats D, Parmar R, Aligeti M (2014) Role of naltrexone in management of behavioral outbursts in an adolescent male diagnosed with disruptive mood dysregulation disorder. J Child Adolesc Psychopharmacol 24 (10):594-595. doi:10.1089/cap.2014.0072 42. Périsse D, Gerardin P, Cohen D, Flament M, Mazet P (2006) Conduct disorder in children and adolescents: a review of current therapeutic approaches. Neuropsychiatrie de l'enfance et de l'adolescence 54:401-410. doi:10.1016/j.neurenf.2005.09.006

43. Zhou X, Hetrick SE, Cuijpers P, Qin B, Barth J, Whittington CJ, Cohen D, Del Giovane C, Liu $Y$, Michael KD, Zhang Y, Weisz JR, Xie P (2015) Comparative efficacy and acceptability of psychotherapies for depression in children and adolescents: A systematic review and network meta-analysis. World Psychiatry 14 (2):207-222. doi:10.1002/wps.20217

44. MacPherson HA, Cheavens JS, Fristad MA (2013) Dialectical behavior therapy for adolescents: theory, treatment adaptations, and empirical outcomes. Clinical child and family psychology review 16 (1):59-80. doi:10.1007/s10567-012-0126-7

45. Goldstein TR, Fersch-Podrat RK, Rivera M, Axelson DA, Merranko J, Yu H, Brent DA, Birmaher B (2015) Dialectical behavior therapy for adolescents with bipolar disorder: results from a pilot randomized trial. J Child Adolesc Psychopharmacol 25 (2):140-149. doi:10.1089/cap.2013.0145 46. Mufson L, Sills R (2006) Interpersonal Psychotherapy for depressed adolescents (IPT-A): an overview. Nordic journal of psychiatry 60 (6):431-437. doi:10.1080/08039480601022397 47. Nelson-Gray RO, Keane SP, Hurst RM, Mitchell JT, Warburton JB, Chok JT, Cobb AR (2006) A modified DBT skills training program for oppositional defiant adolescents: promising preliminary findings. Behav Res Ther 44 (12):1811-1820. doi:10.1016/j.brat.2006.01.004 48. Connor DF, Glatt SJ, Lopez ID, Jackson D, Melloni RH, Jr. (2002) Psychopharmacology and aggression. I: A meta-analysis of stimulant effects on overt/covert aggression-related behaviors in ADHD. J Am Acad Child Adolesc Psychiatry 41 (3):253-261. doi:10.1097/00004583200203000-00004

49. Pappadopulos E, Woolston S, Chait A, Perkins M, Connor DF, Jensen PS (2006)

Pharmacotherapy of aggression in children and adolescents: efficacy and effect size. J Can Acad Child Adolesc Psychiatry 15 (1):27-39

50. Rust J, Golombok S (2009) Modern Psychometrics. The science of psychological assessment. 3 edn., London and New York

51. Leibenluft E, Stoddard J (2013) The developmental psychopathology of irritability. Dev Psychopathol 25 (4 P† 2):1473-1487. doi:10.1017/s0954579413000722

52. Stringaris A, Goodman R, Ferdinando S, Razdan V, Muhrer E, Leibenluft E, Brotman MA (2012) The Affective Reactivity Index: a concise irritability scale for clinical and research settings. J Child Psychol Psychiatry 53 (11):1109-1117. doi:10.1111/j.1469-7610.2012.02561.x 53. Guile JM, Chapdelaine C, Desrosiers L, Cornez C, Bouvier H, Breton JJ (2009) Preliminary reliability study of the affective lability scale adapted for adolescents in a francophone clinical population. J Can Acad Child Adolesc Psychiatry 18 (4):293-306

54. Wagner KD, Kowatch RA, Emslie GJ, Findling RL, Wilens TE, McCague K, D'Souza J, Wamil A, Lehman RB, Berv D, Linden D (2006) A double-blind, randomized, placebo-controlled trial of oxcarbazepine in the treatment of bipolar disorder in children and adolescents. Am J Psychiatry 163 (7):1179-1186. doi:10.1176/ajp.2006.163.7.1179

55. Tohen M, Kryzhanovskaya L, Carlson G, Delbello M, Wozniak J, Kowatch R, Wagner K, Findling R, Lin D, Robertson-Plouch C, Xu W, Dittmann RW, Biederman J (2007) Olanzapine versus placebo in the treatment of adolescents with bipolar mania. Am J Psychiatry 164 (10):1547-1556. doi:10.1176/appi.ajp.2007.06111932

56. Cohen D, Consoli A, Bodeau N, Purper-Ouakil D, Deniau E, Guile JM, Donnelly C (2010) Predictors of placebo response in randomized controlled trials of psychotropic drugs for children and adolescents with internalizing disorders. J Child Adolesc Psychopharmacol 20 (1):39-47. doi:10.1089/cap.2009.0047 
57. Cohen D, Deniau E, Maturana A, Tanguy ML, Bodeau N, Labelle R, Breton JJ, Guile JM (2008) Are child and adolescent responses to placebo higher in major depression than in anxiety disorders? A systematic review of placebo-controlled trials. PloS one 3 (7):e2632. doi:10.1371/journal.pone.0002632

58. Rutherford BR, Sneed JR, Tandler JM, Rindskopf D, Peterson BS, Roose SP (2011)

Deconstructing pediatric depression trials: an analysis of the effects of expectancy and therapeutic contact. J Am Acad Child Adolesc Psychiatry 50 (8):782-795.

doi:10.1016/j.jaac.2011.04.004

59. Henry A, Kisicki MD, Varley C (2012) Efficacy and safety of antidepressant drug treatment in children and adolescents. Mol Psychiatry 17 (12):1 186-1 193. doi:10.1038/mp.2011.150

60. Efron D, Jarman F, Barker M (1997) Side effects of methylphenidate and dexamphetamine in children with attention deficit hyperactivity disorder: a double-blind, crossover trial.

Pediatrics $100(4): 662-666$

61. Ingenhoven TJ, Duivenvoorden HJ (2011) Differential effectiveness of antipsychotics in borderline personality disorder: meta-analyses of placebo-controlled, randomized clinical trials on symptomatic outcome domains. Journal of clinical psychopharmacology 31 (4):489496. doi:10.1097/JCP.0b013e3182217a69

62. Fonagy P, Speranza M, Luyten P, Kaess M, Hessels C, Bohus M (2015) ESCAP Expert Article: borderline personality disorder in adolescence: an expert research review with implications for clinical practice. Eur Child Adolesc Psychiatry 24 (1 1):1307-1320. doi:10.1007/s00787-015$0751-Z$

63. Dvir Y, Ford JD, Hill M, Frazier JA (2014) Childhood maltreatment, emotional dysregulation, and psychiatric comorbidities. Harvard review of psychiatry 22 (3):149-161.

doi:10.1097/HRP.0000000000000014 


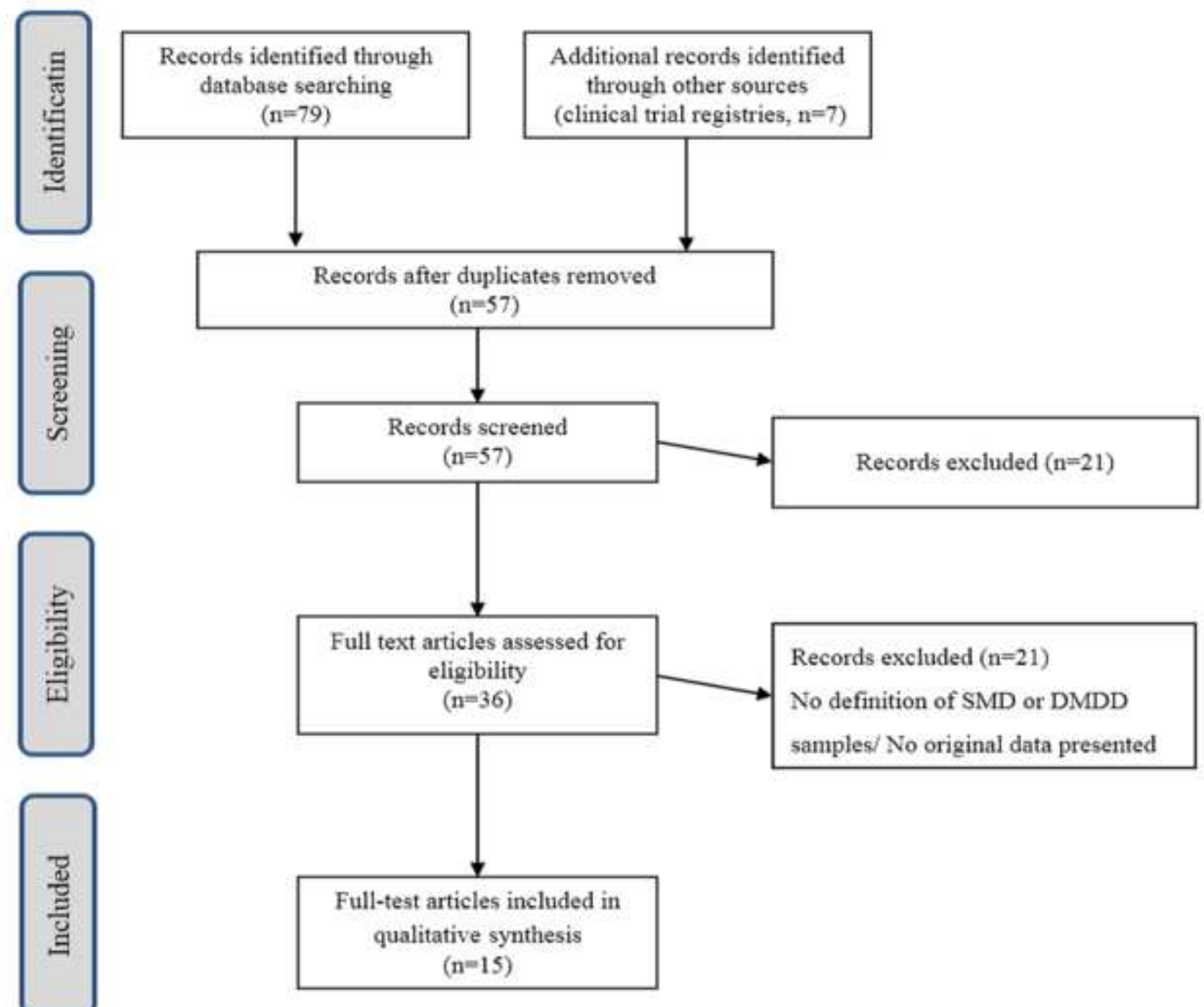

Full-test articles included in $(\mathrm{n}=15)$

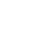


Table 1. Trials evaluating the benefit of psychotherapeutic interventions for youths with SMD or DMDD

\begin{tabular}{|c|c|c|c|c|c|c|c|c|c|}
\hline Authors & $\begin{array}{l}\text { Intervention } \\
\text { Study design }\end{array}$ & $\begin{array}{l}\text { Duration of } \\
\text { study }\end{array}$ & $\begin{array}{l}\mathbf{N} \\
\text { Recruitment }\end{array}$ & $\begin{array}{l}\text { Age } \\
\text { range } \\
\text { (mean) } \\
\text { Gender } \\
\end{array}$ & $\begin{array}{l}\text { Main diagnoses } \\
\text { Inclusion criteria }\end{array}$ & Screening tools & $\begin{array}{l}\text { Psychiatric } \\
\text { comorbidities }\end{array}$ & $\begin{array}{l}\text { Interventions and } \\
\text { control }\end{array}$ & $\begin{array}{l}\text { Scales for main } \\
\text { outcomes } \\
\text { (Mean at baseline) }\end{array}$ \\
\hline $\begin{array}{l}\text { Waxmonsky et al. } \\
2008 \text { [36] }\end{array}$ & $\begin{array}{l}\text { BMOT } \\
\text { Secondary } \\
\text { analysis of } \\
\text { RCT-DB vs. } \\
\text { TAU with } \\
\text { cross-over }\end{array}$ & $\begin{array}{l}\text { Intervention: } 9 \\
\text { weeks }\end{array}$ & $\begin{array}{l}33 \\
\text { Recruited from } \\
\text { schools, } \\
\text { health-care } \\
\text { providers and } \\
\text { public } \\
\text { advertisements }\end{array}$ & $\begin{array}{l}5-12 \text { y.o. } \\
(8.0) \\
\text { Boys } 82 \%\end{array}$ & $\begin{array}{l}\text { ADHD youths meeting } \\
\text { criteria for SMD and } \\
\text { manic-like sympt. } \\
\text { treated with different } \\
\text { doses of MPH }\end{array}$ & $\begin{array}{l}\text { NIMH criteria } \\
\text { for SMD } \\
\text { (items from the } \\
\text { CBCL, DISC) } \\
+ \\
\text { Manic-like } \\
\text { sympt } \\
\text { YMRS (+12) } \\
\text { CGI-S }(+3)\end{array}$ & $\begin{array}{l}\text { ADHD 100\% } \\
\text { ODD 72\% } \\
\text { CD 24\% } \\
\text { Depressive } \\
\text { sympt. (CDRS- } \\
\text { R>28) } 72 \%\end{array}$ & $\begin{array}{l}\text { BMOT } \\
3 \text { weeks each } \\
\text { sessions: no, low } \\
\text { intensity, high } \\
\text { intensity }\end{array}$ & $\begin{array}{l}\text { YMRS (23.7) } \\
\text { CDRS-R (35) } \\
\text { IRS (5.0) } \\
\text { DBD }\end{array}$ \\
\hline $\begin{array}{l}\text { Waxmonsky et al. } \\
2013 \text { [37] }\end{array}$ & $\begin{array}{l}\text { Behavioral } \\
\text { parenting } \\
\text { training } \\
\text { Pilot } \\
\text { monocentric } \\
\text { RCT open- } \\
\text { label vs. TAU }\end{array}$ & $\begin{array}{l}\text { Intervention: } 9 \\
\text { weeks } \\
\text { Follow-up: } 16 \\
\text { weeks }\end{array}$ & $\begin{array}{l}7 \\
\text { Recruited from } \\
\text { an outpatient } \\
\text { clinic }\end{array}$ & $\begin{array}{l}7-12 \text { y.o. } \\
(8.7) \\
\text { Boys } \\
100 \%\end{array}$ & $\begin{array}{l}\text { ADHD (combined } \\
\text { subtypes) youths } \\
\text { meeting criteria for } \\
\text { SMD treated with MPH }\end{array}$ & $\begin{array}{l}\text { NIMH criteria } \\
\text { for SMD } \\
\text { (depression and } \\
\text { mania items } \\
\text { from the } \\
\text { WASH-U- } \\
\text { KSADS) }\end{array}$ & $\begin{array}{l}\text { ADHD 100\% } \\
\text { ODD - NA } \\
\text { CD - NA } \\
\text { SAD 29\% }\end{array}$ & $\begin{array}{l}\text { CBT+ BPT } \\
\text { behavioral parental } \\
\text { training } \\
105 \text {-minute } \\
\text { concurrent parent and } \\
\text { child meetings }\end{array}$ & $\begin{array}{l}\text { YMRS (23.7) } \\
\text { CDRS-R (35) } \\
\text { DBD } \\
\text { CGAS } \\
\text { APQ }\end{array}$ \\
\hline Stoddard et al. [13] & $\begin{array}{l}\text { IBT-SMD } \\
\text { Pilot } \\
\text { monocentric } \\
\text { non-controlled } \\
\text { open-label }\end{array}$ & $\begin{array}{l}\text { Intervention:6 } \\
\text { days } \\
\text { Follow-up: } 2 \\
\text { weeks }\end{array}$ & $\begin{array}{l}14 \\
\text { NA }\end{array}$ & $\begin{array}{l}8-18 \text { y.o. } \\
(14.1) \\
\text { Boys: } \\
47 \%\end{array}$ & $\begin{array}{l}\text { Lifetime diagnosis of } \\
\text { DMDD and clinically } \\
\text { significant DMDD } \\
\text { symptoms (CGI-S } \geq 3 \text { ) }\end{array}$ & $\begin{array}{l}\text { DSM-5 criteria } \\
\text { for DMDD }\end{array}$ & $\begin{array}{l}\text { ADHD 71\% } \\
\text { ODD } 100 \% \\
\text { ANX 71\% } \\
\text { MDD } 14 \%\end{array}$ & $\begin{array}{l}4 \text { sessions of the } \\
\text { active training IBT } \\
\text { task }\end{array}$ & $\begin{array}{l}\text { Parent- and self-report } \\
\text { ARI } \\
\text { SCARED } \\
\text { STAXI-2 C/A } \\
\text { CDI } \\
\text { "Balance point" as a } \\
\text { cognitive marker of } \\
\text { angry judgment bias }\end{array}$ \\
\hline
\end{tabular}




\begin{tabular}{|c|c|c|c|c|c|c|c|c|c|}
\hline $\begin{array}{l}\text { http://www.clinicalt } \\
\text { rials.gov } \\
\text { NCT01862549 } \\
\text { USA } \\
\text { (Cornell University) }\end{array}$ & $\begin{array}{l}\text { DBT-C } \\
\text { Pilot } \\
\text { monocentric } \\
\text { RCT open- } \\
\text { label vs. TAU }\end{array}$ & $\begin{array}{l}\text { Intervention: } 32 \\
\text { weeks } \\
\text { Follow-up: } 12 \\
\text { weeks }\end{array}$ & $\begin{array}{l}60 \text { (target } \\
\text { sample) } \\
\text { NA }\end{array}$ & $\begin{array}{l}7-12 \text { y.o. } \\
\text { Both } \\
\text { genders }\end{array}$ & $\begin{array}{l}\text { DMDD youths may be } \\
\text { medicated if stabilized } \\
\text { for at least } 6 \text { weeks }\end{array}$ & $\begin{array}{l}\text { DSM-5 criteria } \\
\text { for DMDD }\end{array}$ & NA & $\begin{array}{l}2 \text { pre-treatment and } \\
24 \text { treatment sessions, } \\
\text { once per week }(30 \\
\text { min. individual child } \\
\text { therapy, } 20 \text { min. } \\
\text { meeting with a } \\
\text { caregiver and } 40 \text { min. } \\
\text { of skills training with } \\
\text { both) }\end{array}$ & $\begin{array}{l}\text { CGI-I } \\
\text { MSQ } \\
\text { ERC } \\
\text { ARI } \\
\text { MAVRIC } \\
\text { SSRS } \\
\text { C-SSIS }\end{array}$ \\
\hline $\begin{array}{l}\text { http://www.clinicalt } \\
\text { rials.gov } \\
\text { NCT01591564 } \\
\text { USA } \\
\text { (Johns Hopkins } \\
\text { University, NIMH) }\end{array}$ & $\begin{array}{l}\text { IPT-SMD } \\
\text { Pilot } \\
\text { monocentric } \\
\text { non-controlled } \\
\text { open-label }\end{array}$ & $\begin{array}{l}\text { Intervention: } 16 \\
\text { weeks } \\
\text { No follow-up }\end{array}$ & $\begin{array}{l}5 \text { (target } \\
\text { sample) } \\
\text { NA }\end{array}$ & $\begin{array}{l}13-17 \text { y.o. } \\
\text { Both } \\
\text { genders }\end{array}$ & $\begin{array}{l}\text { SMD youths may be } \\
\text { medicated if stabilized } \\
\text { for at least } 4 \text { weeks } \\
+ \\
\text { CGAS } \leq 60\end{array}$ & $\begin{array}{l}\text { NIMH criteria } \\
\text { for SMD }\end{array}$ & NA & $\begin{array}{l}\text { once per week; } 16 \\
\text { weeks }\end{array}$ & CGI-I \\
\hline $\begin{array}{l}\text { http://www.clinicalt } \\
\text { rials.gov } \\
\text { NCT01962623 } \\
\text { USA } \\
\text { (Johns Hopkins } \\
\text { University, NIMH) } \\
\end{array}$ & $\begin{array}{l}\text { IPT-MBD } \\
\text { Pilot } \\
\text { monocentric } \\
\text { RCT-SB vs. } \\
\text { TAU }\end{array}$ & $\begin{array}{l}\text { Intervention: } 24 \\
\text { weeks } \\
\text { No follow-up }\end{array}$ & $\begin{array}{l}44 \text { (target } \\
\text { sample) } \\
\text { NA }\end{array}$ & $\begin{array}{l}12-17 \text { y.o. } \\
\text { Both } \\
\text { genders }\end{array}$ & $\begin{array}{l}\text { SMD youths } \\
+ \\
\text { CGAS } \leq 60 \\
\text { CGI-S } \geq 4\end{array}$ & $\begin{array}{l}\text { NIMH criteria } \\
\text { for SMD }\end{array}$ & NA & $\begin{array}{l}\text { once per week; } 24 \\
\text { weeks }\end{array}$ & CGI-I \\
\hline $\begin{array}{l}\text { http://www.clinicalt } \\
\text { rials.gov } \\
\text { NCT02531893 } \\
\text { USA } \\
\text { (NIMH) }\end{array}$ & $\begin{array}{l}\text { CBT vs. IBT } \\
\text { Pilot } \\
\text { monocentric } \\
\text { open-label }\end{array}$ & $\begin{array}{l}\text { Intervention: } 10 \\
\text { weeks } \\
\text { No follow up }\end{array}$ & $\begin{array}{l}40 \text { (target } \\
\text { sample) } \\
\text { NA }\end{array}$ & $\begin{array}{l}8-18 \text { y.o. } \\
\text { Both } \\
\text { genders }\end{array}$ & $\begin{array}{l}\text { DMDD, ADHD, ODD } \\
\text { youths may be } \\
\text { medicated (no delay } \\
\text { period) } \\
+ \\
\text { CGI-S } \geq 3\end{array}$ & DSM-5 criteria & NA & $\begin{array}{l}4 \text { sessions over } 4 \text { days } \\
\text { and } 8 \text { weeks of } \\
\text { weekly booster } \\
\text { sessions }\end{array}$ & $\begin{array}{l}\text { CGI-I } \\
\text { ARI }\end{array}$ \\
\hline
\end{tabular}

BMOT: Behavior Modification therapy; RCT: Randomized controlled trial; DB: Double-blind; TAU: Treatment-as-usual; y.o.: year old; NA: Not Available; Sympt.:

Symptoms; SB: Single-blind; MPH: Methylphenidate; CBCL: Child Behavior Checklist; DISC: Diagnostic Interview Schedule for Children; YMRS: the Young Mania Rating Scale; CDRS-R: the Children's Depression Rating Scale Revised; IRS: Impairment Rating Scale; DBD: Disruptive Behavior Disorders Rating Scale; WASH-U-KSADS: the Washington University in St. Louis Kiddie Schedule for Affective Disorders and Schizophrenia; CGAS: the Children's Global Assessment Scale; APQ: the Alabama Parenting Questionnaire; MSQ: Mood Symptoms Questionnaire; ERC: Emotion Regulation Checklist; ARI: Affective Reactivity Index; MAVRIC: Measure of Aggression Violence and Rage in Children; SSRS: Social Skills Rating Scale; C-SSIS: Columbia Suicide and Self-Injury Severity Rating Scale; IBT: Interpretation Bias Training 
Table 2. Trials evaluating the benefit of pharmacological treatments for youths with SMD or DMDD

\begin{tabular}{|c|c|c|c|c|c|c|c|c|c|c|}
\hline Authors & $\begin{array}{l}\text { Intervention } \\
\text { Study design }\end{array}$ & $\begin{array}{l}\text { Duration of } \\
\text { study }\end{array}$ & $\begin{array}{l}\mathbf{N} \\
\text { Recruitment }\end{array}$ & 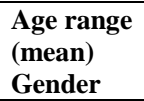 & $\begin{array}{l}\text { Main diagnoses } \\
\text { Inclusion criteria }\end{array}$ & Screening tools & $\begin{array}{l}\text { Psychiatric } \\
\text { comorbidities }\end{array}$ & $\begin{array}{l}\text { Interventions and } \\
\text { control }\end{array}$ & $\begin{array}{l}\text { Scales for main } \\
\text { outcomes }\end{array}$ & Main results \\
\hline $\begin{array}{l}\text { Waxmonsky et } \\
\text { al. } 2008 \text { [36] }\end{array}$ & $\begin{array}{l}\text { MPH } \\
\text { Secondary analysis } \\
\text { of RCT-DB vs. } \\
\text { PBO with cross- } \\
\text { over }\end{array}$ & $\begin{array}{l}\text { Intervention: } 9 \\
\text { weeks }\end{array}$ & $\begin{array}{l}33 \\
\text { Recruited from } \\
\text { schools, } \\
\text { health-care } \\
\text { providers and } \\
\text { public } \\
\text { advertisements }\end{array}$ & $\begin{array}{l}5 \text {-12 y.o. } \\
\text { (8) } \\
\text { Boys } 82 \%\end{array}$ & $\begin{array}{l}\text { ADHD youths } \\
\text { meeting criteria for } \\
\text { SMD and manic-like } \\
\text { sympt.treated with } \\
\text { different intensity of } \\
\text { psychotherapy }\end{array}$ & $\begin{array}{l}\text { NIMH criteria } \\
\text { for SMD } \\
\text { (items from } \\
\text { CBCL, DISC) } \\
+ \\
\text { Manic-like } \\
\text { sympt } \\
\text { YMRS (+12) } \\
\text { CGI (+3) }\end{array}$ & $\begin{array}{l}\text { ADHD 100\% } \\
\text { ODD 72\% } \\
\text { CD 24\% } \\
\text { Depressive } \\
\text { sympt. (CDRS- } \\
\text { R>28) 72\% }\end{array}$ & $\begin{array}{l}\text { MPH } 0.15 \mathrm{mg} / \mathrm{kg} \text {, } \\
0.3 \mathrm{mg} / \mathrm{kg}, 0.6 \mathrm{mg} / \mathrm{kg}\end{array}$ & $\begin{array}{l}\text { YMRS (23.7) } \\
\text { CDRS-R (35) } \\
\text { IRS (5.0) } \\
\text { DBD }\end{array}$ & $\begin{array}{l}34 \% \text { decrease in } \\
\text { YMRS score } \\
31 \% \text { in CDRS-R } \\
\text { score } \\
\text { Improvement in } \\
\text { externalizing } \\
\text { symptoms } \\
\text { Improvement in } \\
\text { overall impairment }\end{array}$ \\
\hline $\begin{array}{l}\text { Dickstein et al. } \\
2009 \text { [24] }\end{array}$ & $\begin{array}{l}\text { Lithium } \\
\text { PRP, } \\
\text { RCT-DB vs. PBO }\end{array}$ & $\begin{array}{l}\text { Intervention: } 6 \\
\text { weeks }\end{array}$ & $\begin{array}{l}25 \\
\text { Recruited via } \\
\text { advertisements, } \\
\text { on support } \\
\text { groups' websites } \\
\text { and via } \\
\text { psychiatrists }\end{array}$ & $\begin{array}{l}7-17 \text { y.o. } \\
(11.5) \\
\text { Boys } 75 \%\end{array}$ & SMD youths & $\begin{array}{l}\text { NIMH criteria } \\
\text { for SMD } \\
\text { (K-SADS-PL } \\
\text { with an } \\
\text { additional SMD } \\
\text { module) }\end{array}$ & $\begin{array}{l}\text { ADHD 92\% } \\
\text { ODD 88\% } \\
\text { CD - NA } \\
\text { MDD 20\% } \\
\text { SAD 12\% }\end{array}$ & $\begin{array}{l}\text { Lithium carbonate } \\
\text { between } 0.8-1.2 \\
\mathrm{mEq} / 1\end{array}$ & $\begin{array}{l}\text { PANSS factor } 4 \\
\text { YMRS (14.6) } \\
\text { CDRS (29.8) } \\
\text { CGI-S (4.9) } \\
\text { CGAS (44.7) } \\
\text { Conners' teacher } \\
\text { OAS } \\
\text { CGI-I }\end{array}$ & $\begin{array}{l}\text { No significant } \\
\text { differences in CGI-I } \\
\text { or PANSS scores. }\end{array}$ \\
\hline $\begin{array}{l}\text { Krieger et al. } \\
2011[40]\end{array}$ & $\begin{array}{l}\text { Risperidone } \\
\text { Pilot monocentric } \\
\text { non-controlled } \\
\text { open-label }\end{array}$ & $\begin{array}{l}\text { Intervention:8 } \\
\text { week } \\
\text { Follow-up } 8 \\
\text { weeks }\end{array}$ & $\begin{array}{l}21 \\
\text { Recruited via } \\
\text { advertisements }\end{array}$ & $\begin{array}{l}\text { 7-17 y.o. } \\
(10.4) \\
\text { Boys } 43 \%\end{array}$ & SMD youths & $\begin{array}{l}\text { NIMH criteria } \\
\text { for SMD } \\
\text { (K-SADS-PL } \\
\text { with an } \\
\text { additional SMD } \\
\text { module) }\end{array}$ & $\begin{array}{l}\text { ADHD 71\% } \\
\text { ODD 81\% } \\
\text { CD 14\% } \\
\text { MDD 14\% } \\
\text { AD 71\% }\end{array}$ & $\begin{array}{l}\text { Risperidone } 0.5 \text { to } 3 \\
\mathrm{mg} / \mathrm{d} \text { (mean } 1.28 \mathrm{mg} \text { ) }\end{array}$ & $\begin{array}{l}\text { ABC-Irritability (25.9) } \\
\text { SNAP-IV (1.71) } \\
\text { YMRS (12.7) } \\
\text { CDRS (34.3) } \\
\text { CGI-S (4.5) } \\
\text { CGAS (46.9) } \\
\text { MSQ (37.4) } \\
\text { SCARED (34.7) }\end{array}$ & $\begin{array}{l}56 \% \text { decrease in } \\
\text { ABC-irritability } \\
64 \% \text { decrease in } \\
\text { YMRS } \\
34 \% \text { decrease in } \\
\text { CDRS } \\
34 \% \text { increase of } \\
\text { CGAS }\end{array}$ \\
\hline $\begin{array}{l}\text { Parmar et al. } \\
2014 \text { [41] }\end{array}$ & $\begin{array}{l}\text { Naltrexone } \\
\text { Case report }\end{array}$ & 3 months & 1 inpatient & $\begin{array}{l}15 \text { y.o. } \\
\text { Boy }\end{array}$ & DMDD youths & $\begin{array}{l}\text { DSM- } 5 \text { criteria } \\
\text { for DMDD }\end{array}$ & ADHD & Naltrexone $50 \mathrm{mg} / \mathrm{d}$ & No & $\begin{array}{l}\text { Significant } \\
\text { improvement in } \\
\text { aggressive symptoms }\end{array}$ \\
\hline
\end{tabular}




\begin{tabular}{|c|c|c|c|c|c|c|c|c|c|c|}
\hline $\begin{array}{l}\text { http://www.clin } \\
\text { icaltrials.gov } \\
\text { NCT01714310 } \\
\text { USA } \\
\text { (University of } \\
\text { California, } \\
\text { NIMH) }\end{array}$ & $\begin{array}{l}\text { LDX combined or } \\
\text { not with Fluoxetine } \\
\text { Monocentric open- } \\
\text { label period } \\
\text { followed by RCT- } \\
\text { DB vs. PBO }\end{array}$ & $\begin{array}{l}\text { Intervention:1 } \\
\text { 2 weeks } \\
\text { (Open-label } \\
\text { LDX: } 4 \text { weeks; } \\
\text { CRT-DB } \\
\text { Fluoxetine vs. } \\
\text { PBO: } 8 \text { weeks) } \\
\text { Follow-up } \\
\text { period } 4 \text { weeks }\end{array}$ & $\begin{array}{l}50 \text { (target } \\
\text { sample) } \\
\text { NA }\end{array}$ & $\begin{array}{l}7-17 \text { y.o. } \\
\text { Both } \\
\text { genders }\end{array}$ & $\begin{array}{l}\text { Youths with both } \\
\text { SMD and ADHD } \\
\text { criteria }\end{array}$ & $\begin{array}{l}\text { NIMH criteria } \\
\text { for SMD } \\
+ \\
\text { inattentive or } \\
\text { hyperactive/Im } \\
\text { pulsive } \\
\text { subscales } \\
\text { ADHD-RS }>9 \\
+ \\
\text { ABC }<12\end{array}$ & NA & $\begin{array}{l}\text { LDX low, medium, } \\
\text { and high dose } \\
\text { Fluoxetine }\end{array}$ & $\begin{array}{l}\text { Safety/Efficacy } \\
\text { CGI-I } \\
\text { PARS } \\
\text { CDRS } \\
\text { ADHD-IV RS } \\
\text { CSSS } \\
\text { CALS } \\
\text { R-MOAS } \\
\text { ARI }\end{array}$ & $\mathrm{NA}$ \\
\hline $\begin{array}{l}\text { http://www.clin } \\
\text { icaltrials.gov } \\
\text { NCT00794040 } \\
\text { USA } \\
\text { (NIMH) }\end{array}$ & $\begin{array}{l}\text { MPH combined or } \\
\text { not with Citalopram } \\
\text { PRP, } \\
\text { Open-label period } \\
\text { followed by } \\
\text { RCT-DB vs. PBO }\end{array}$ & $\begin{array}{l}\text { Intervention:4- } \\
5 \text { months } \\
\text { Medication } \\
\text { withdrawal } \\
\text { PRP: 1 week } \\
\text { Open-label } \\
\text { MPH: 5weeks } \\
\text { CRT-DB } \\
\text { Citalopram vs } \\
\text { PBO: } 8 \text { weeks } \\
\text { Open } \\
\text { treatments } \\
\text { phase: } 10 \\
\text { weeks }\end{array}$ & $\begin{array}{l}160 \text { (target } \\
\text { sample) } \\
\text { NA }\end{array}$ & $\begin{array}{l}7-17 \text { y.o } \\
\text { Both } \\
\text { genders }\end{array}$ & SMD youths & $\begin{array}{l}\text { SMD + ADHD } \\
+ \\
+ \\
\text { CGAS } \leq 60\end{array}$ & $\mathrm{NA}$ & $\begin{array}{l}\text { Methylphenidate + } \\
\text { Citalopram: } 20-40 \\
\text { mg/d }\end{array}$ & $\begin{array}{l}\text { Safety/Efficacy } \\
\text { CGI-I } \\
\text { ABC-Irritability }\end{array}$ & NA \\
\hline $\begin{array}{l}\text { http://www.clin } \\
\text { icaltrials.gov } \\
\text { NCT02063945 } \\
\text { Israel } \\
\text { (Sheba Medical } \\
\text { Center) }\end{array}$ & $\begin{array}{l}\text { Risperidone vs. } \\
\text { Methylphenidate } \\
\text { Open label } \\
\text { randomized }\end{array}$ & $\begin{array}{l}\text { Intervention: } 8 \\
\text { weeks }\end{array}$ & $\begin{array}{l}70 \text { (target } \\
\text { sample) } \\
\text { NA }\end{array}$ & $\begin{array}{l}5-18 \text { y.o } \\
\text { Both } \\
\text { genders. }\end{array}$ & $\begin{array}{l}\text { ADHD youths with } \\
\text { comorbid disruptive } \\
\text { disorder (ODD/CD) }\end{array}$ & $\begin{array}{l}\text { ADHD + ODD } \\
\text { or CD or } \\
\text { DMDD }\end{array}$ & NA & $\begin{array}{l}\text { Methylphenidate } \\
\text { (Ritaline } \mathrm{LA} \mathrm{A}^{\circledast}: 0.6 \text { to } \\
1.5 \mathrm{mg} / \mathrm{kg} / \mathrm{day} ; \\
\text { Concerta }: 1 \text { to } 2 \\
\mathrm{mg} / \mathrm{kg} / \mathrm{day}) \text { vs. } \\
\text { Risperidone ( } 0.5 \text { to } 2 \\
\mathrm{mg} / \text { day) }\end{array}$ & $\begin{array}{l}\text { Safety/Efficacy } \\
\text { R-MOAS } \\
\text { CGI-I } \\
\text { CGI-S } \\
\text { ADHD-RS } \\
\text { CDRS } \\
\text { YMRS } \\
\text { CSHQ }\end{array}$ & NA \\
\hline
\end{tabular}

PBO: Placebo; PRP: pre-randomization run-in period; PANSS: the Positive and Negative Syndrome Scale (factor 4= sum of excitement, hostility, uncooperativeness, and poor impulse control); OAS: Overt Aggression Scale; SNAP-IV: the Swanson, Nolan, and Pelham Scale-version IV; SCARED: Screen for Child Anxiety-Related Emotional Disorders; LDX: Lisdexamfetamine; PARS: the Pediatric Anxiety Rating Scale; ADHD-RS: the ADHD-IV Rating Scale; CSSS: the Columbia Suicide Severity Scale; CALS: the Children's Affective Lability Scale; R-MOAS: the Revised Modified Overt Aggression Scale; CSHQ: the Children Sleep Habits Questionnaire 
Table 3. Trials evaluating the benefit of psychotherapeutic interventions for youths with SMD or DMDD

\begin{tabular}{|c|c|c|c|c|}
\hline Authors & $\begin{array}{l}\text { USPSTF's } \\
\text { grade }^{\text {a }}\end{array}$ & Main results & Limitations & Strengths \\
\hline \multicolumn{5}{|c|}{ Psychotherapeutic studies } \\
\hline $\begin{array}{l}\text { Waxmonsky et al. } \\
2008 \text { [36] }\end{array}$ & Level II-1 & $\begin{array}{l}34 \% \text { decrease in YMRS } \\
\text { score } \\
31 \% \text { in CDRS-R score } \\
\text { Improvement in } \\
\text { externalizing symptoms } \\
\text { Improvement in overall } \\
\text { impairment }\end{array}$ & $\begin{array}{l}\text { - Selected sample size (already enrolled in the STP study) } \\
\text { - Use of psychometric instruments nonstandardized (YMRS for } \\
\text { SMD criteria) } \\
\text { - Only one assessment instrument for the measure of } \\
\text { SMD/DMDD symptoms } \\
\text { - Complex cross-over design (two within-subjects factors) not } \\
\text { clear if change attributable to medication or psychotherapy } \\
\text { - No procedures to evaluate treatment adherence } \\
\text { - No follow-up evaluation of treatment effects }\end{array}$ & $\begin{array}{l}\text { - Size of the sample } \\
\text { - Description of the treatments detailed } \\
\text { - Measure of tolerability provided } \\
\text { - Teacher-report information } \\
\text { - LOCF analysis }\end{array}$ \\
\hline $\begin{array}{l}\text { Waxmonsky et al. } \\
2013 \text { [37] }\end{array}$ & Level II-3 & $\begin{array}{l}\text { Decrease in CDRS-R } \\
d=1.17, \text { YMRS } d=0.81, \\
\text { DBD (ADHD } d=0.30, \text { ODD } \\
d=0.26, \text { CD } d=0.27), \text { C-GAS } \\
(d=2.17) \\
\text { Decrease in parenting } \\
\text { behavior (parental } \\
\text { involvement } d=-0.37 \text { and } \\
\text { inconsistent } \\
\text { discipline } d=0.46)\end{array}$ & $\begin{array}{l}\text { - Small sample size } \\
\text { - Sample bias: only boys included, only combined subtype of } \\
\text { ADHD } \\
\text { - Use of psychometric instruments nonstandardized (YMRS for } \\
\text { SMD criteria) } \\
\text { - Only one assessment instrument for the measure of } \\
\text { SMD/DMDD symptoms } \\
\text { - Non-comparative design } \\
\text { - No follow-up evaluation of treatment effects }\end{array}$ & $\begin{array}{l}\text { - Ethnic diversity within sample } \\
\text { - Assessment of comorbidity and respect of } \\
\text { exclusion criteria (ASD, ID) } \\
\text { - Description of the treatments detailed } \\
\text { - Low level of drop-out rate among families } \\
\text { - Measure of treatment fidelity }\end{array}$ \\
\hline Stoddard et al. [13] & Level II-3 & $\begin{array}{l}\text { Decrease of balance point } \\
\text { (away from angry judgment } \\
\text { bias) } \beta=2.25 \text { morphs. } \\
\text { CGI-I in the "slightly } \\
\text { improved"' range }(d=0.59) \\
\text { Decrease parent-report ARI } \\
\text { score } \beta=-1.57 \text { points, no } \\
\text { significant change in self- } \\
\text { report ARI }\end{array}$ & $\begin{array}{l}\text { - Selected sample size ( } 22 \% \text { of the initial sample) } \\
\text { - Possible sample bias, no information is provided about the } \\
\text { recruiting method } \\
\text { - Non-comparative design } \\
\text { - Only four session of treatment are tested and follow-up } \\
\text { evaluation was planned at } 2 \text { weeks } \\
\text { - Symptom changes were modest and remained in clinical } \\
\text { range, results on "balance point" is difficult to interpret }\end{array}$ & $\begin{array}{l}\text { - Use of DMDD criteria } \\
\text { - Use of two standardized psychometric } \\
\text { instruments for the measure of DMDD } \\
\text { symptoms (ARI, CGI-I) } \\
\text { - Use of both parent and self-report } \\
\text { information } \\
\text { - Description of the treatments detailed } \\
\text { - Measure of "balance-point" suggests } \\
\text { possible mechanisms for treatment efficacy }\end{array}$ \\
\hline
\end{tabular}




\begin{tabular}{|c|c|c|c|c|}
\hline $\begin{array}{l}\text { NCT01862549 } \\
\text { USA }\end{array}$ & - & NA & $\begin{array}{l}\text { - Sample bias: only younger than } 13 \text { year olds } \\
\text { - Assessors were not blinded } \\
\text { - Lack of no-treatment control group }\end{array}$ & $\begin{array}{l}\text { - Use of DMDD criteria } \\
\text { - Randomization } \\
\text { - Twelve-weeks follow-up evaluation of } \\
\text { treatment effects } \\
\text { - At least two assessment instrument for the } \\
\text { measure of SMD/DMDD symptoms } \\
\text { - Measure of compliance }\end{array}$ \\
\hline $\begin{array}{l}\text { NCT01591564 } \\
\text { USA }\end{array}$ & - & NA & $\begin{array}{l}\text { - Small sample size } \\
\text { - Sample bias: only older than } 13 \text { year olds } \\
\text { - Only one assessment instrument for the measure of SMD } \\
\text { symptoms } \\
\text { - Non-comparative design } \\
\text { - No follow-up evaluation of treatment effects }\end{array}$ & - Measure of compliance \\
\hline $\begin{array}{l}\text { NCT01962623 } \\
\text { USA }\end{array}$ & - & NA & $\begin{array}{l}\text { - Lack of no-treatment control group } \\
\text { - No follow-up evaluation of treatment effects } \\
\text { - Only one assessment instrument for the measure of SMD } \\
\text { symptoms }\end{array}$ & $\begin{array}{l}\text { - Size of the sample (expected) } \\
\text { - Randomization } \\
\text { - Single-blind (Outcomes Assessor) } \\
\text { - Measure of satisfaction }\end{array}$ \\
\hline $\begin{array}{l}\text { NCT02531893 } \\
\text { USA }\end{array}$ & - & NA & $\begin{array}{l}\text { - No follow-up evaluation of treatment effects } \\
\text { - Assessors and participants were not blind } \\
\text { - Findings from the arm with both forms of therapy with a } 4 \\
\text { weeks wash-out periods would be difficult to interpret } \\
\text { - Non randomized allocations of treatments }\end{array}$ & $\begin{array}{l}\text { - Size of the sample (expected) } \\
\text { - Diversity in terms of age, prescribed } \\
\text { medication } \\
\text { - Use of DMDD criteria }\end{array}$ \\
\hline \multicolumn{5}{|c|}{ Pharmacological studies } \\
\hline $\begin{array}{l}\text { Waxmonsky et al. } \\
2008 \text { [36] }\end{array}$ & Level II-1 & $\begin{array}{l}34 \% \text { decrease in YMRS } \\
\text { score } \\
31 \% \text { in CDRS-R score } \\
\text { Improvement in } \\
\text { externalizing symptoms } \\
\text { Improvement in overall } \\
\text { impairment }\end{array}$ & $\begin{array}{l}\text { - Selected sample size (already enrolled in the STP study) } \\
\text { - Use of psychometric instruments nonstandardized (YMRS for } \\
\text { SMD criteria) } \\
\text { - Only one assessment instrument for the primary outcome } \\
\text { measure } \\
\text { - Complex cross-over design (two within-subjects factors) not } \\
\text { clear if change attributable to medication or psychotherapy } \\
\text { - No procedures to evaluate treatment adherence } \\
\text { - No follow-up evaluation of treatment effects }\end{array}$ & $\begin{array}{l}\text { - Size of the sample } \\
\text { - Description of the treatments detailed } \\
\text { - Measure of tolerability provided } \\
\text { - Teacher-report information } \\
\text { - LOCF analysis }\end{array}$ \\
\hline $\begin{array}{l}\text { Dickstein et al. } 2009 \\
\text { [24] }\end{array}$ & Level II-1 & $\begin{array}{l}\text { No significant differences in } \\
\text { CGI-I or PANSS scores. }\end{array}$ & $\begin{array}{l}\text { - Selected sample bias: community-based recruitment via } \\
\text { advertisements, assessment of only a sample of those initially } \\
\text { screened }(\approx 23 \%) \\
\text { - Use of psychometric instruments nonstandardized (YMRS for } \\
\text { SMD criteria) } \\
\text { - No comparison to a well-validated treatment } \\
\text { - No follow-up evaluation of treatment effects }\end{array}$ & $\begin{array}{l}\text { - Exclusion criteria and the prevalence of } \\
\text { psychiatric comorbidity are detailed } \\
\text { - Two-weeks placebo run-in period } \\
\text { - Randomization } \\
\text { - Assessors and participants were blind } \\
\text { - Intent-to-treat analysis with LOCF } \\
\text { - Measure of tolerability provided }\end{array}$ \\
\hline
\end{tabular}




\begin{tabular}{|c|c|c|c|c|}
\hline $\begin{array}{l}\text { Krieger et al. } 2011 \\
\text { [40] }\end{array}$ & Level II-2 & $\begin{array}{l}56 \% \text { decrease in ABC- } \\
\text { irritability } \\
64 \% \text { decrease in YMRS } \\
34 \% \text { decrease in CDRS } \\
34 \% \text { increase of CGAS }\end{array}$ & $\begin{array}{l}\text { - Selected sample bias: community-based recruitment via } \\
\text { advertisements, no current use of medication, little socio- } \\
\text { economic diversity } \\
\text { - Use of psychometric instrument nonstandardized (YMRS for } \\
\text { SMD criteria) } \\
\text { - Non-comparative design }\end{array}$ & $\begin{array}{l}\text { - Exclusion criteria and the prevalence of } \\
\text { psychiatric comorbidity are detailed } \\
\text { - Description of the treatments detailed } \\
\text { - At least two assessment instrument for the } \\
\text { measure of SMD symptoms } \\
\text { - Follow-up evaluation of treatment effects } \\
\text { - Weekly measure of tolerability }\end{array}$ \\
\hline $\begin{array}{l}\text { Parmar et al. } 2014 \\
\text { [41] }\end{array}$ & Level II-3 & $\begin{array}{l}\text { Significant improvement in } \\
\text { aggressive symptoms }\end{array}$ & $\begin{array}{l}\text { - Case report of a single case } \\
\text { - Non-comparative design } \\
\text { - No use of standardized psychometric instrument } \\
\text { - No follow-up evaluation of treatment effects }\end{array}$ & - Use of DMDD criteria \\
\hline NCT01714310 & - & NA & $\begin{array}{l}\text { - Selected sample bias: only ADHD youths } \\
\text { - No procedures to evaluate the effect of Fluoxetine in naive } \\
\text { participants (without Lisdexamfetamine) } \\
\text { - No active-drug/placebo run-in period } \\
\text { - Multiple scales used (risk of multiple statistical testing) }\end{array}$ & $\begin{array}{l}\text { - Size of the sample (expected) } \\
\text { - Randomization } \\
\text { - Assessors and participants were blind } \\
\text { - Measure of tolerability provided }\end{array}$ \\
\hline NCT00794040 & - & NA & $\begin{array}{l}\text { - No procedures to evaluate the effect of Citalopram in naive } \\
\text { participants (without Methylphenidate) } \\
\text { - Only one assessment instrument for SMD symptoms }\end{array}$ & $\begin{array}{l}\text { - Size of the sample (expected) } \\
\text { - Randomization } \\
\text { - Assessors and participants were blind } \\
\text { - Pre-randomization phases (medication } \\
\text { withdrawal period and 1-week placebo run- } \\
\text { in period) } \\
\text { - Measure of tolerability provided }\end{array}$ \\
\hline NCT02063945 & - & NA & $\begin{array}{l}\text { - Selected sample bias: only ADHD youths with disruptive } \\
\text { disorders } \\
\text { - Use of psychometric instruments nonstandardized (YMRS, R- } \\
\text { MOAS) } \\
\text { - Assessors and participants were not blind } \\
\text { - Lack of no-treatment control group } \\
\text { - No active-drug/placebo run-in period }\end{array}$ & $\begin{array}{l}\text { - Size of the sample (expected) } \\
\text { - Randomization } \\
\text { - Measure of tolerability provided }\end{array}$ \\
\hline
\end{tabular}

a The level of evidence presented in each paper was categorized using the United States Preventive Services Task Force (USPSTF) criteria. Level I evidence denotes having at least one well-designed RCT supporting a treatment's possible efficacy. Level II-1 requires a well-designed controlled trial without randomization, level II-2 requires at least one well-designed cohort or case-control study, and level II-3 requires a multiple time series design. We excluded level III evidence (opinions of respected authorities based on clinical experience or descriptive studies) from our review. 